\title{
Paraphyletic species
}

\author{
Michael D. Crisp and Greg T. Chandler
}

\begin{abstract}
Crisp, Michael D. and Chandler, Gregory T. (Division of Botany and Zoology, The Australian National University, Canberra ACT 0200, Australia) 1996. Paraphyletic species Telopea 6(4): 813-844. We present evidence, mainly from plants, that many recognised species and subspecies are paraphyletic. Whilst some cladists have argued that species are like other taxa, and should be monophyletic, it is clear that even cladists either implicitly or explicitly recognise nonmonophyletic species. Moreover, species concepts such as the phylogenetic species concept and the composite species concept predict non-monophyly of many species. Whenever a monophyletic species is circumscribed, it is possible that a paraphyletic or metaphyletic 'residual' species is simultaneously recognised. Furthermore, attempts to place all organisms in a monophyletic taxon at every rank regress to the population level where monophyly is no longer applicable, leaving paraphyletic residuals. These groups of organisms can hardly be ignored, unless one wishes to define them out of existence (as in the monophyletic species concept). It has been argued that paraphyly is only an artifact of the Linnean system, which requires all organisms to be classified in certain ranks, e.g. species. However the phenonemon of regress shows that this is incorrect, because paraphyly is inherent in species. The solution to this conundrum is to recognise species as special taxa, which may be monophyletic or paraphyletic. (Higher taxa should always be monophyletic, and can be made so.) This requires the acceptance of a species concept that allows paraphyly, such as the phylogenetic species concept or the composite species concept. The monophyletic species concept, which does not allow paraphyly, is not acceptable. The special nature of species derives from their basal position in the phylogenetic system. Theoretically, the proportion of paraphyletic and metaphyletic species may be $50 \%$ or higher. Empirical estimates range from $20 \%$ to $50 \%$. Use of non-monophyletic species in historical applications such as biogeography is widespread but may not be invalid, depending upon the assumptions made.
\end{abstract}

\section{Introduction}

In recent years, systematists have sought a species concept that is compatible with a phylogenetic system. They have rejected the biological species concept because of its reliance on the single criterion of reproduction. Entities which are distinct in many evolutionary, biological, and ecological features are nevertheless capable of interbreeding (Endler 1989, pp. 629-30). The biological species concept has never dealt satisfactorily with the conundrum of potentially (but not actually) interbreeding allopatric populations. Above all, the biological species concept is based on contemporary micro-evolutionary processes and cannot be reconciled with a phylogenetic system, in which taxa are viewed as historical units, extended in time and the units of a nested hierarchy (Rosen 1979; Donoghue 1985; Cracraft 1989; Vrana \& Wheeler 1992; Frost \& Kluge 1995).

\section{Species as lineages}

Systematists have debated whether species should be viewed as lineages or taxa (Nelson 1989b; Rieppel 1994; Frost \& Kluge 1995). Recent views of species as lineages hark back to a model presented by Hennig (1966: fig. 6), showing a lineage of sexually reproducing organisms splitting into two daughter linages. Each lineage is 
made internally cohesive by reticulating ('tokogenetic') relationships among its component organisms, but no such connections exist between lineages - they are mutually exclusive. Species are the internodes of a phylogenetic tree and speciation is the point at which lineages split permanently. Hennig's model has been reproduced many times, with modifications to show details or complications such as temporary versus permanent splits, reticulation and extinction (Kornet 1993a; Kornet 1993b; O'Hara 1993; Frost \& Kluge 1995; Graybeal 1995). Most importantly, a lineage species is a model of evolutionary process. It is viewed as a real entity that evolves in time and space, has a definite beginning and end, and may be the ancestor of lineages comprising one or many species. It has been called the 'evolutionary species concept' (Wiley 1981; Frost \& Kluge 1995) and the 'internodal species concept' (Nixon \& Wheeler 1990; Kornet 1993a).

Some authors have been preoccupied with 'exclusivity' of lineage species (Donoghue 1985; de Queiroz \& Donoghue 1988; de Queiroz \& Donoghue 1990a; de Queiroz \& Donoghue 1990b; Baum 1992; Baum \& Shaw 1995; Graybeal 1995). (This is often called 'monophyly' but strictly monophyly refers to a taxon diagnosed by an autapomorphy.) A lineage is exclusive only if all its members are more closely related to one another (by ancestry) than to any member of another lineage. For example, the lineage of descendants of Queen Victoria is not exclusive because some descendants are more closely related to members of other lineages (by marriage, e.g. cousins). This discussion can reduce to the absurd because any lineage may be shown to be non-exclusive if examined minutely enough, even body cells (Frost \& Kluge 1995). In her formalisation of a lineage concept of species, Kornet (1993a) shows that internodal species are mutually exclusive partitions of the genealogical network. Whilst this is a different notion of exclusivity from that discussed above, Kornet shows the latter problem to be irrelevant by using descent rather than ancestry as the criterion of group membership.

\section{Species as taxa}

A major problem with species conceived as lineages is that they have poor empirical content (Kornet 1993a). When we find two allopatric populations that are essentially similar, we have no way of judging their fate - whether they are the basis of new, historically separate lineages, whether either will become extinct, or whether they will reunite and become reproductively, tokogenetically cohesive again. Therefore, systematists have also proposed concepts of species that have an empirical basis. In this view, species are part of a pattern of similarity among organisms: the hierarchy of internested groups that are called taxa (Nelson \& Platnick 1981; Nelson 1989b; Rieppel 1994). The internested groups or taxa are recognised by shared similarity in characters, known as synapomorphy or homology. This hierarchy is represented as a tree (cladogram or phylogeny), but it is an abstract representation of pattern. The branches of the tree represent taxonomic groups which are internested, static and do not evolve. Thus the stem at the base of the angiosperms represents not the ancestral species of all angiosperms, but the most inclusive set of all taxa that we call angiosperms, recognised by the set of characters that all angiosperms share, and marked on the stem. Rieppel (1994) suggests that species conceived as lineages and species conceived as taxa are 'complementary but incompatible'. (Frost \& Kluge (1995) refer to this distinction as the 'scalar' hierarchy versus the 'specification' hierarchy.) If taxa are also considered to be ancestors and descendants, then we are confronted with a paradox (Nelson 1989b). For example, does the subordination of the angiosperms to the seed plants imply that the seed plants are the ancestors of the angiosperms? Surely not, because the angiosperms are also a part of seed plants, 
and angiosperms are not ancestors of themselves, any more than I am part of my grandfather. However, it cannot be disputed that some member of the seed plants evolved into the first angiosperm. The resolution of this paradox is to recognise taxa as units of an hierarchical pattern, not as part of the evolutionary process. By logical extension, species belong to this hierarchy. This pattern, when reconstructed, may be used as a framework for hypotheses about the evolutionary process, e.g. that a seed plant with certain characteristics gave rise to the first angiosperm. Thus the role of ancestor is restricted to lineages and their subunits, such as individuals or populations (Rieppel 1994) or 'internodons' (Kornet 1993b). If species are treated as taxa, then they are not different in kind from higher taxa. They are simply the least inclusive units in the systematic hierarchy.

Recent concepts of species as phylogenetic taxa derive from Nelson \& Platnick (1981: 12), who define species as 'the smallest diagnosable cluster of self-perpetuating organisms that have unique sets of characters'. This is known as the 'phylogenetic species concept', 'irreducible unit' or 'minimum diagnosable unit' (Cracraft 1989; Nixon \& Wheeler 1990; Nixon \& Wheeler 1992). However, a unique or diagnostic character may be either an apomorphy or a plesiomorphy, and a group diagnosed solely by the latter is not monophyletic, which is anathema to authors such as Nelson (1989a; 1989b). Such species are not simple internodal partitions of a phylogenetic tree. They 'survive' a speciation event in which an autapomorphic species branches off from the phylogenetic stem (Nixon \& Wheeler 1992: fig. 4.7B). Contrast this with Hennig's (1966: fig. 6) methodological extinction of ancestral species at branch-points. Neither Cracraft nor Nixon and Wheeler confront the paraphyly issue, but instead imply that paraphyletic species are acceptable, provided that they manifest unique and fixed character combinations. Under the phylogenetic species concept, speciation is the point at which a lineage acquires an apomorphy, or more precisely. when a new character is fixed (Nixon \& Wheeler 1992: fig. 4.7). This is true even of species diagnosed by a plesiomorphy, because at some point earlier in history, every plesiomorphy was an apomorphy. A problem with the notion of an 'irreducible unit'. is that it is prone to regress (cf. de Queiroz \& Donoghue 1990b). Peripherally isolated populations in which trivial genetic characters can easily become fixed would be diagnosed as species, contrary to general practice. One solution to the paraphyly problem is the monophyletic species concept, under which species have at least one autapomorphy (Rosen 1979; Donoghue 1985; Nelson 1989a; Nelson 1989b). However, this concept is unsatisfactory because ultimately taxa are not necessarily divisible into monophyletic sister-taxa (Smith '1994b). The smallest autapomorphic unit may have as its sister-group an unresolved symplesiomorphic cluster of organisms. The autopomorphic species concept consigns these to limbo, outside any species, but they can scarcely be ignored.

Some authors have taken the pragmatic view that phenetic clusters may be treated as species. This approach has been termed the 'phenetic species concept', although it is actually an empirical criterion, free of assumptions about evolutionary process. Such units have been termed 'phena' (Mayr 1969; Smith 1994b), to distinguish them from theoretically based 'species'. In fact, the phenetic species concept is the formal equivalent of the traditional 'taxonomic' or 'morphological' species concept, under which species are circumscribed by intuitively perceived similarity among their members (Sneath \& Sokal 1973: 364-5). Sometimes this concept is conflated with the phylogenetic species concept; however, clustering by overall similarity is not the same as clustering by diagnostic (fixed) characters. Clusters in phenetic space may share no diagnostic character; usually they are circumscribed by a series of partially correlating (polythetic) characters. Nevertheless, some authors have argued that phenetic clusters may be equivalent in practice to phylogenetic species (Theriot 1992; Crisp \& Weston 1993). 
The composite species concept (Kornet 1993b), as its name implies, combines the lineage and taxon views of species. Kornet first formalises the internodal species concept (Kornet 1993a) then reveals a significant drawback with it: every isolated population is a potential new lineage and it can be made permanent by extinction. Thus, internodal species tend to be trivial units compared with those that are generally recognised as species, and are more akin to populations. Moreover, the internodal species concept is operationally intractable, because the fate of an isolated population cannot be determined. Instead, Kornet defines composite species as lineages of 'internodons' which begin with the fixation of a novel character in an ancestral internodon and end with another fixation in a descendant internodon (or extinction). Composite species are parts of lineages because internodons have ancestor-descendant relationships and are mutually exclusive. Because they are diagnosed by fixed novel characters (autapomorphies), they are also taxa and operationally equivalent to phylogenetic species. Thus the composite species concept seems to reconcile the tension between species-as-lineages and species-as-taxa (above). It should be noted that composite species are paraphyletic groups of internodons, unless they become extinct, in which case they become monophyletic (Kornet 1993b: 69).

\section{Paraphyly and metaphyly}

Cladism has led to rejection of paraphyletic taxa on the grounds that they are not real phylogenetic units and lead to confusion about both the distribution of characters and the relationships of taxa (Donoghue \& Cantino 1988; Humphries \& Chappill 1988). Paraphyletic groups are considered 'artifactual' and qualitatively different from monophyletic groups, which are 'real' taxa (Nelson 1989b). For every monophyletic taxon recognised, any of a series of paraphyletic groups may be constructed by excluding the monophyletic taxon from more inclusive (higher-level) monophyletic groups. In this way, paraphyletic groups have been treated as taxa, diagnosed by symplesiomorphies or the absence of the autapomorphies which circumscribe the excluded monophyletic groups. When taxa are discovered to be paraphyletic, systematists are inclined to divide them into several more narrowly circumscribed, monophyletic taxa (monophyly can also be achieved by amalgamation). However, this process of division may regress to the species level, where a problem is encountered: species are not divisible into monophyletic subunits. Moreover, both the phylogenetic species concept and the related composite species concept predict that many, if not most, species are not monophyletic (above). Here is a conundrum: if species are to be considered taxa, logically the sanction against paraphyly should apply to them (Cracraft 1989; Nelson 1989a; Nelson 1989b).

Empirically, it has long been recognised that many accepted species are paraphyletic ('paraspecies': Ackery \& Vane-Wright 1984). In a paraspecies, some (but not all) members are more closely related to members of another species than to other members of the paraspecies. Evidence for paraphyly would be a synapomorphy which some members of the paraspecies share with the other species (Fig. 1c). Some authors have pointed out that any species that lacks an evident autapomorphy is at least potentially paraphyletic; however, this is only an inference based on lack of evidence (it is also potentially monophyletic). The term 'metaspecies' has been coined (Donoghue 1985) to distinguish such species (whose phylogenetic status has not been resolved by cladistic analysis) from paraspecies (whose presumed monophyly has been tested and refuted). (Gauthier (1986) extends the metataxon concept to higher taxa but this is not relevant here.) Phylogenetic analysis of populations comprising a metaspecies may have one of three outcomes (cf. de Queiroz \& Donoghue 1988: fig. 7): (i) a synapomorphy may be found for all populations, and 

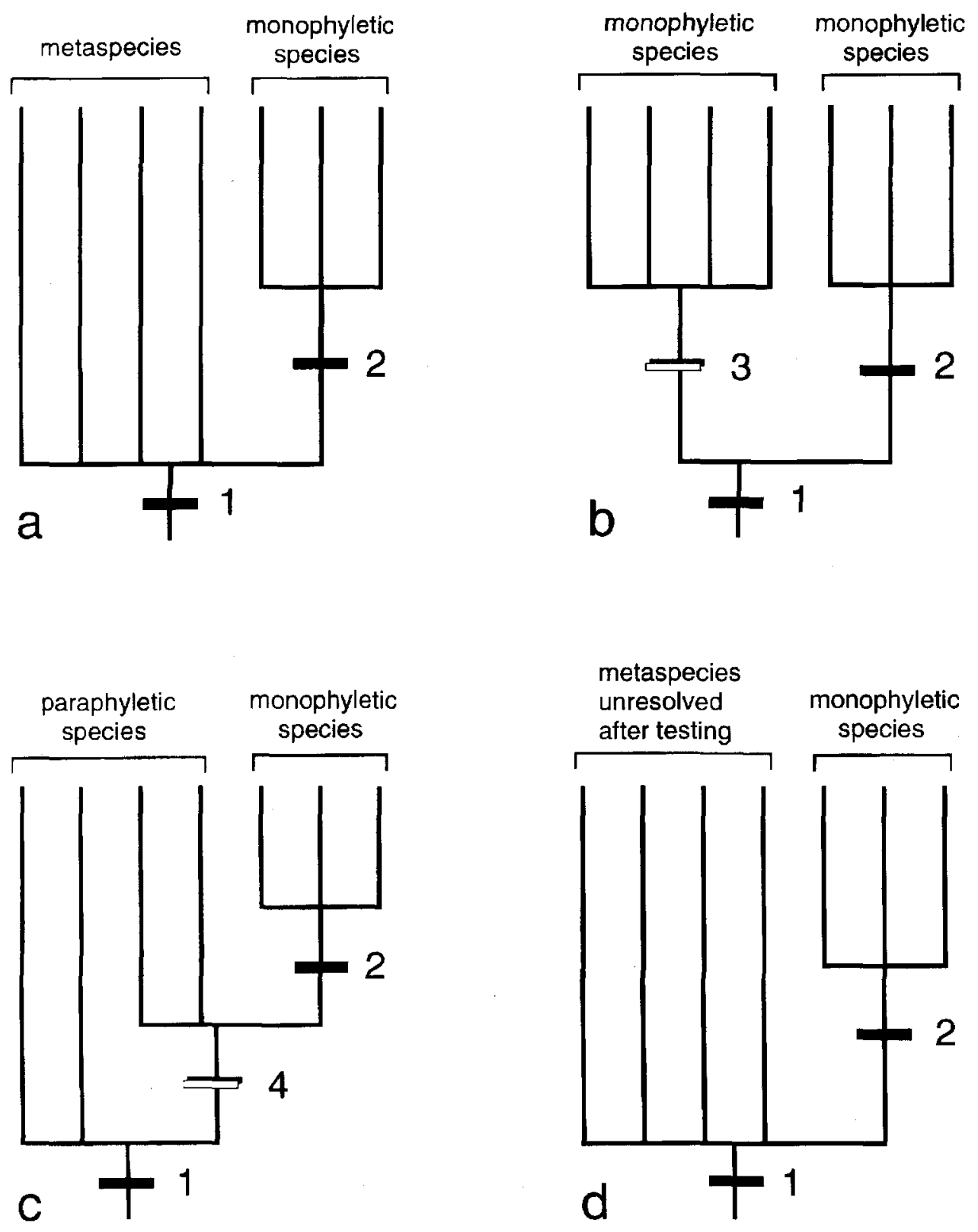

Fig. 1. Illustration of monophyletic species, paraspecies (paraphyletic) and metaspecies (unresolved). a, Initial phylogeny showing a metaspecies as sister-group to a monophyletic species. The metaspecies has no apomorphic characters except 1, which it shares with its sister species. The monophyletic species has an autapomorphy, character 2 . b-d, Possible outcomes following cladistic analysis of populations in $\mathbf{a} . \mathbf{b}$, A new synapomorphy (character 3) is found for populations comprising the metaspecies, which is now recognised as a monophyletic species. c, A new synapomorphy (character 4) is found which is shared by two populations of the metaspecies and the monophyletic sister species. The original metaspecies is now recognised to be paraphyletic. d, No further apomorphies are found, and the metaspecies remains unresolved. These definitions apply equally to subspecies. Terminal branches represent populations. Solid bars represent original apomorphies; open bars represent additional apomorphies discovered following cladistic analysis. 
the 'metaspecies' is shown to be monophyletic (Fig. 1b); (ii) a synapomorphy may be found (character 4, Fig. 1c) demonstrating that some populations of the metaspecies are more closely related to a recognised monophyletic species, in which case the 'metaspecies' is shown to be paraphyletic; (iii) no new apomorphy is found, and the species remains an unresolved metaspecies (Fig. 1d), diagnosed only by a symplesiomorphy (character 1, Fig. 1d). Both paraspecies and metaspecies are diagnosed by symplesiomorphy (character 1, respectively in Figs. 1c and 1d). However, they differ in that evidence exists to show that part of the paraspecies is more closely related to another species (character 4 in Fig. 1c), whereas no such evidence is found in a metaspecies (Fig. 1d). To summarise, depending upon the observed distribution of apomorphies among populations, the phylogenetic status of a species may be: unresolved (a metaspecies), non-monophyletic (a paraspecies) or monophyletic (an autapomorphic species). Note that irrespective of the phylogenetic relationship of their populations, all these species are diagnosable units consistent with the phylogenetic and composite species concepts. Therefore all are real, discoverable and corroborable entities. Moreover, the phylogenetic relationship of their parts (monophyletic, paraphyletic or metaphyletic) is also discoverable and corroborable (by the adducement of additional evidence).

\section{Objectives}

In this paper, we present examples of paraspecies and metaspecies and empirically estimate their proportion of all species. We show that any attempt to purge the system of these is futile, because of the asymmetric distribution of apomorphic (relatively advanced) characters among basal lineages (species). Consequently we address the conundrum of paraspecies and metaspecies in a system to which these are anathema. Finally, we consider the implications for comparative methods such as cladistic biogeography of a false assumption of species monophyly.

For the purpose of this paper, we make no fundamental distinction between species and subspecies. This paper is concerned with lowest-level taxa, whether ranked as species or subspecies. The concepts monophyly, paraphyly and metaphyly apply equally to either, and to taxa of any rank. We do not consider the effects of reticulation, as this is a separate problem.

\section{Examples of paraspecies}

The following five examples report cladistic analyses using as terminals either populations or geographic forms that do not have evident autapomorphies and may well be paraphyletic. Are these suitable units for cladistic analysis? Some authors suggest that using paraphyletic terminals invalidates phylogenetic analysis (Cracraft 1989; de Queiroz \& Donoghue 1990a; de Queiroz \& Donoghue 1990b; Nixon \& Wheeler 1990; Wheeler \& Nixon 1990; Vrana \& Wheeler 1992). Moreover, because evolution among populations is likely to be reticulate, the strictly hierarchical model of cladistic relationships may be invalidated (Crisp \& Weston 1993). However, these problems are not restricted to populations: the monophyly of most taxa (e.g. species and subspecies) is untested and thus uncertain (Nelson 1989b). Moreover, this paper shows that many such taxa are probably paraphyletic. An extensive literature attests to the frequency of reticulate evolution among recognised species (e.g., Funk 1985; Barton \& Hewitt 1989; Harrison 1991; Arnold 1992; Grant \& Grant 1992; Smith 1992). Thus, problems affecting cladistic analysis of populations apply at least in part to subspecies and species. Vrana \& Wheeler (1992) advocate using as terminals individual organisms, whose monophyly can (perhaps) be safely presumed. However, 
their approach is likely to encounter serious sampling problems: if the terminals comprising a data set are too sparse a sample of the variation within the study group, then an incorrect topology may be found because divergent change may confound estimates of homology. This is becoming evident in studies using molecular data (Melnick et al. 1993; Smith 1994a), as well as fossils (Donoghue et al. 1989: 444-449). By analogy, a single individual may be an inadequate sample of the character variation within a species or higher taxon. Clearly cladistic analysis cannot, by the nature of its assumptions and limitations, reconstruct all the historical events affecting populations, such as reticulation or isolation of a lineage in which no detectable apomorphy has evolved. However, it should retrieve the major divergence events as well supported clades, and on this basis we shall proceed.

\section{Daviesia ulicifolia}

Recently we have attempted to resolve the complex species Daviesia ulicifolia (Fabaceae: Mirbelieae). As currently circumscribed, this taxon extends from Cape York Peninsula in far north Queensland $\left(16^{\circ} \mathrm{S}, 145^{\circ} \mathrm{E}\right)$ south to Tasmania $\left(43^{\circ} \mathrm{S}, 147^{\circ} \mathrm{E}\right)$ and west to the Great Victoria Desert $\left(30^{\circ} \mathrm{S}, 124^{\circ} \mathrm{E}\right)$. This is a vast range: $27^{\circ}$ in latitude and $23^{\circ}$ in longitude; however, the distribution is ' $\mathrm{L}$ '-shaped and only covers about $20 \%$ of the Australian continent. Additionally, in south-eastern mainland Australia, it extends from sea-level to tree-line at $1800 \mathrm{~m}$ altitude, where continuous snow cover is experienced in winter months. Not surprisingly, this is a polytypic species showing several morphological forms. Bentham (1864: 81) named four forms (under the illegitimate name $D$. ulicina), but neither he nor his successors have produced a satisfactory classification of the species. Our treatment used mainly morphometric characters of the leaves, stems, inflorescence and flowers to identify phenetic clusters that might be recognised as taxa. Although several morphologicgeographic clusters were evident, most of these intergraded in the regions of overlap, and we have treated them either as subspecies or informal forms (Table 1; Chandler \& Crisp, in prep.). Environmental variables such as soil texture, nutrients and climatic parameters correlate with the clusters but these too overlap between forms. The only form which we are segregating at species level is the 'Yorke' form, which is autapomorphic and appears more closely related to $D$. arthropoda than to D. ulicifolia (Fig. 2; Chandler \& Crisp, in prep.).

We have made a cladistic analysis of the forms of $D$. ulicifolia and related species which share with it a distinctive kind of calyx with equal teeth (D. acicularis, D. arenaria, D. arthropoda and D. microcarpa: Pate et al. 1989; Crisp 1995a). At this low taxonomic level, most of the available characters are morphometric in nature, and we used the coding method of Thiele (1993a). The few qualitative characters tend to be autapomorphies for the recognised species (Table 1), for example: toothed and revolute leaf margins (D. acicularis); midrib more prominent abaxially (D. arenaria); leaves angular-terete, stems lax and unbranched (D. microcarpa). Both $D$. arthropoda and $D$. ulicifolia lack autapomorphies and should be considered a priori metaspecies. For an outgroup we used $D$. wyattiana, which appears to be closely related to the D. ulicifolia group (Pate et al. 1989). Tables 2 and 3 show the character list and data matrix respectively.

We used the 'branch and bound' algorithm in PAUP (Swofford 1990) to find a single most parsimonious tree of 396 steps (Fig. 2). The data set shows significant cladistic structure (PTP < 0.01: Faith \& Cranston 1991). However, the low bootstrap values on most nodes indicate a weak hierarchical pattern in the characters used. Little phylogenetic structure is expected at the level of diverging geographic forms, because they are unlikely to be fully differentiated lineages due to reticulation or gene flow, even if this occurs at a reduced level compared with undifferentiated populations 
Table 1. Terminal taxa used in the cladistic analysis of Daviesia ulicifolia. Autapomorphies (unique defining characters) are indicated where known.

\section{Name}
D. wyattiana
D. acicularis
D. arenaria
D. arthropoda
D. microcarpa
D. Ulicifolia:

angustifolia

desert

grampians

lofty

NVP

pilliga

ruscifolia

subumbellate

typical

yorke

\section{Distribution}

Eastern Great Dividing Range

NSW, mainly coast and ranges

Mallee, NSW, VIC, SA

Central Australia

Norseman, WA

East coast, $\mathrm{N}$ of Hunter Valley

Southern arid interior, WA to NSW

Grampians, western Victoria

Mt Lofty Range, SA

Northern plains, VIC

Pilliga scrub, NSW

Montane to subalpine,

$\mathrm{VIC}$ and NSW

mainly lowland Victoria

Coastal south-eastern Australia

Yorke Peninsula (SA);

eastern Tas

\section{Autapomorphies}

Linear leaves

Leaf margins toothed, revolute

Midrib prominent below

Minute standard petal

Leaves angular-terete;

unbranched

\section{Plant pruinose;}

uniflorescence racemose

Standard petal red

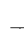

Leaves very thick, rigid, wrinkled

Table 2. Characters used in the cladistic analysis of Daviesia ulicifolia. All characters are continuous variables normalised by log transformation, except qualitative characters, as indicated.

1. Leaf length

2. Leaf width

3. Leaf shape (ratio distance from tip to widest point: length)

4. Leaf cross section (ratio thickness: width, at widest point)

5. Standard width

6. Inflorescence type: $0=$ solitary, $1=$ umbel, $2=$ raceme

7. Peduncle length

8. Rachis length

9. Pedicel length

10. Midrib: $0=$ more prominent above, 1 = equal, $2=$ more prominent below (unordered)

11. Divaricate habit: $0=$ yes, $1=$ no

12. Spinescent branchlets: $0=$ yes, $1=$ no 
Table 3. Data matrix used in the cladistic analysis of Daviesia ulicifolia. Values for each character are standardised integers over the range 0 to 30 using the method of Thiele (1994). A polymorphism is indicated by ' $p$ ' (states 1 and 2).

$\begin{array}{lcccccccccccc}\text { D. myattiana } & 30 & 20 & ? & 4 & 29 & 1 & 30 & 0 & 30 & 1 & 1 & 1 \\ \text { D. acicularis } & 12 & 13 & 17 & 6 & 11 & 0 & 0 & 0 & 5 & 0 & 1 & 1 \\ \text { D. arenaria } & 2 & 30 & 16 & 0 & 12 & 0 & 0 & 0 & 8 & 2 & 0 & 0 \\ \begin{array}{l}\text { D. arthropoda } \\ \text { D. microcarpa }\end{array} & 14 & 26 & 0 & 2 & 0 & 0 & 14 & 0 & 17 & 0 & 0 & 0 \\ \begin{array}{l}\text { D. ulicifolia: } \\ \quad\end{array} & & 30 & 30 & 8 & 0 & 0 & 0 & 10 & ? & 1 & 1 \\ \text { angustifolia } & 6 & 1 & 25 & 12 & 11 & 0 & 0 & 0 & 0 & 0 & 0 & 0 \\ \text { desert } & 7 & 13 & 22 & 10 & 5 & 2 & 7 & 30 & 8 & 0 & 0 & 0 \\ \text { grampians } & 7 & 20 & 16 & 5 & 30 & 1 & 6 & 0 & 9 & 0 & 0 & 0 \\ \text { lofty } & 9 & 14 & 20 & 7 & 27 & p & 7 & 2 & 8 & 0 & 0 & 0 \\ \quad \text { NVP } & 0 & 20 & 26 & 3 & 3 & 0 & 0 & 0 & 2 & 0 & 0 & 0 \\ \quad \text { pilliga } & 6 & 26 & 17 & 1 & 6 & 0 & 0 & 0 & 3 & 0 & 0 & 0 \\ \quad \text { ruscifolia } & 3 & 18 & 28 & 4 & 26 & 0 & 0 & 0 & 7 & 0 & 0 & 0 \\ \quad \text { subumbellate } & 6 & 13 & 24 & 7 & 22 & 1 & 5 & 0 & 5 & 0 & 0 & 0 \\ \quad \text { typical } & 5 & 13 & 22 & 5 & 16 & 0 & 3 & 0 & 6 & 0 & 0 & 0 \\ \quad \text { yorke } & 12 & 28 & 3 & 2 & 22 & 1 & 11 & 0 & 12 & 0 & 0 & 0\end{array}$

(de Queiroz \& Donoghue 1988; Crisp \& Weston 1993). Nevertheless one clade with a moderate bootstrap value of 67 included all forms of $D$. ulicifolia and the three autapomorphic species D. acicularis, D. arenaria and D. microcarpa (Fig. 2). Thus D. ulicifolia appears to be paraphyletic by exclusion of the latter species. Only the 'Yorke' form is excluded from this clade, and it shows a sister-group relationship to $D$. arthropoda. As the species included within the D. ulicifolia clade are well separated, no re-rooting can make D. ulicifolia appear monophyletic, even if the distinct 'Yorke' is excluded from consideration. We tried constraining monophyly of $D$. ulicifolia, but this increased tree-length very substantially (68 extra steps), a significant difference which was not achieved in 100 randomised data sets (T-PTP $<0.01$ : Faith 1991). Other manipulations, such as selectively excluding combinations of species, did not substantially alter the relationships of the forms nor alter the paraphyly of D. ulicifolia. An alternative binary encoded data set (with fewer characters) produced a very unresolved tree but again showed $D$. ulicifolia as paraphyletic.

\section{Banksia integrifolia}

Thiele (1993b) and Thiele \& Ladiges (1994) made a morphological analysis of the Banksia integrifolia (Proteaceae: Banksieae) complex, which broadly overlaps with D. ulicifolia east of the Great Dividing Range. Their methods were essentially similar to those described above for D. ulicifolia, using either binary or morphometric characters of adult leaves, fruits and juvenile leaves. Four phenetic clusters were recognised as taxa. Three of these overlapped in distribution and morphology. Only the most northern entity ('aquilonia') was found to be both morphologically and geographically disjunct, with no intermediates. The authors would have liked to segregate this as a species, but demurred on the basis of a cladistic analysis, which nested aquilonia deep within the complex (Fig. 3). Thus, B. integrifolia would have been rendered paraphyletic by 
removal of aquilonia. To circumvent this problem, they might have split $B$. integrifolia into four species (corresponding to the four phenetic-geographic clusters), but they refrained because of the existence of intermediates between most of the clusters. Instead, they described the four forms as subspecies of $B$. integrifolia.

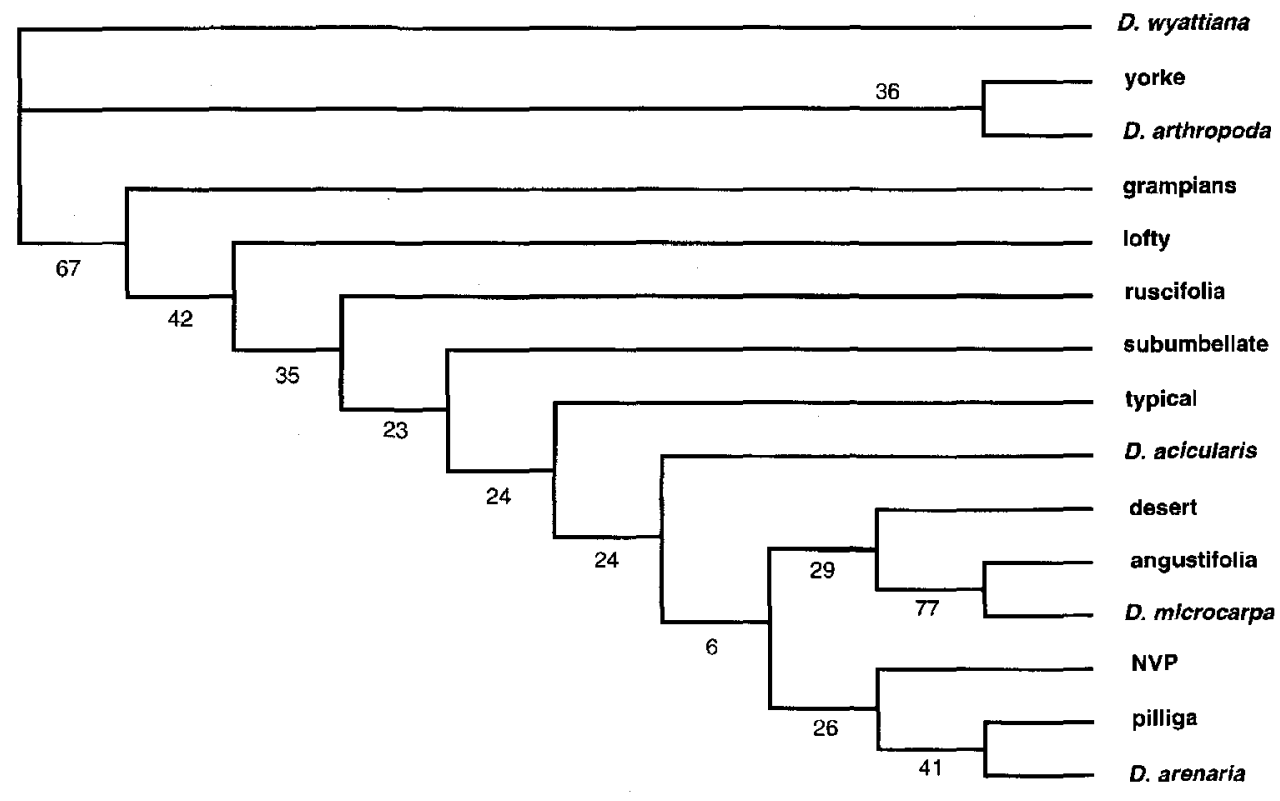

Fig. 2. Shortest tree ( 396 steps) for geographic forms of Daviesia ulicifolia (in plain font) and related species (in italics, preceded by ' $D$. '). Found using 'branch and bound' in PAUP 3.1.1 (Swofford 1990) from data in Table 3 . Numbers on internodes indicate bootstrap values from 100 replicates. The tree is rooted using the outgroup $D$. wyattiana. Note that $D$. ulicifolia is paraphyletic by inclusion of four other species.

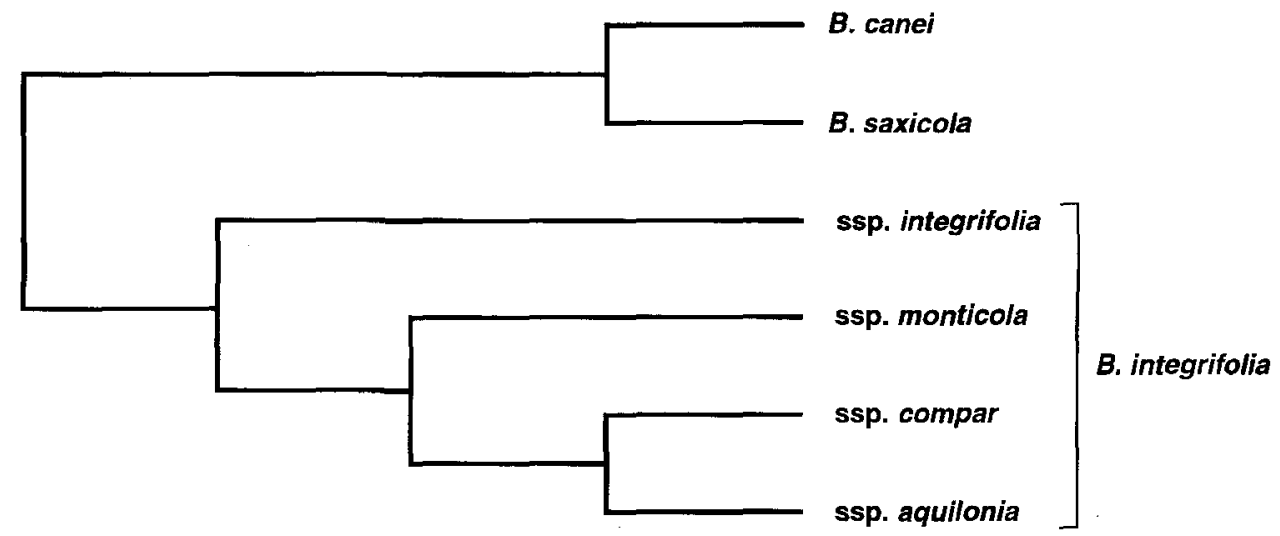

Fig. 3. Cladogram of Banksia integrifolia comprising four subspecies (integrifolia, monticola, compar and aquilonia) and its sister-group, comprising the species B. canei and B. saxicola, from Thiele (1993b). Note that if aquilonia were segregated as a species, the remainder of $B$. integrifolia would be rendered paraphyletic. 
Thiele and Ladiges made it clear that they did not wish to define species to which some specimens could not be reliably assigned (due to intergradation). However, they also rejected an alternative taxonomic solution of segregating only the distinctive entity aquilonia for the implicit reason that this would create a paraphyletic species: 'However, its terminal position in the cladogram precludes separating it as a distinct species without also raising the other taxa to species rank' (Thiele \& Ladiges 1994: 403). They did not actually mention the term 'paraphyletic', nor discuss directly the problems associated with paraphyletic taxa. Nevertheless, the B. integrifolia complex as described by them is directly analagous to the D. ulicifolia complex, because it is a monophyletic group comprising a paraphyletic basal group of incompletely differentiated geographic forms within which is nested at least one divergent, autapomorphic taxon that invites treatment as a species.

\section{Eucalyptus caesia}

Eucalyptus caesia (Myrtaceae: Leptospermioideae) is a mallee (many stems arising from a woody lignotuber) confined to granite outcrops in south-west Western Australia. It has several evident autapomorphies including pendulous inflorescences, pink or red flowers, distinctive urceolate fruit shape with a descending disc, and ovules in 6 rows (Hopper \& Burgman 1983; Brooker \& Kleinig 1990). Two subspecies are recognised, subsp. magna and subsp. caesia, the latter having been segregated because of its red flowers, pendulous branchlets and larger leaves, buds, flowers and fruits (Brooker \& Hopper 1982; Brooker \& Kleinig 1990). The granite outcrops that are its exclusive habitat are naturally isolated from one another by a few to many kilometers, and thus the populations are well-defined and lend themselves to phylogenetic anaysis.

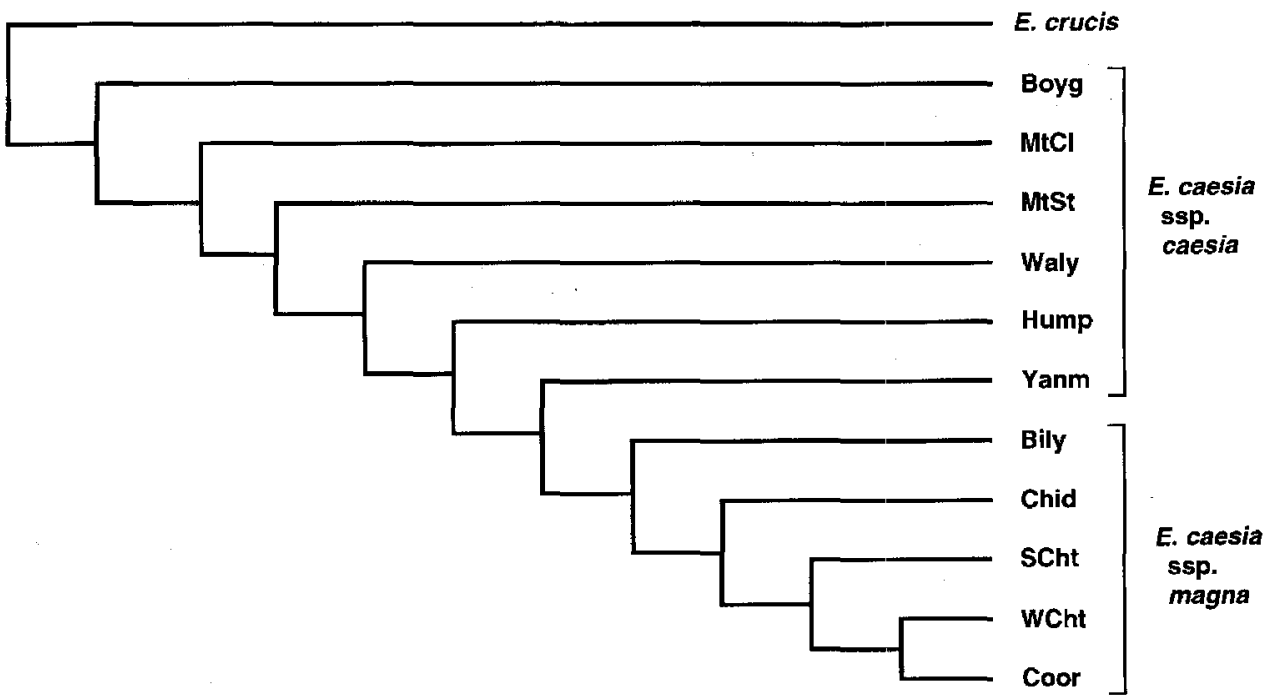

Fig. 4. Phylogeny of Eucalyptus caesia populations, derived by parsimony analysis using combined allozyme frequency and morphometric data (Hopper \& Burgman 1983: fig. 3b). The tree is rooted using the outgroup E. crucis subsp. lanceolata. Key to populations, all in the wheatbelt of Western Australia: SCht, S of Chutawalakin Hill; WCht, W of Chutawalakin Hill; Chid, Chiddarcooping Hill; Coor, Coorancooping Hill; Yanm, Yanneymooning Hill; Waly, Walyahmoning Rock; Bily, Billyacating Hill; Hump, The Humps; Boyg, Boyagin Rock; $\mathrm{MtCl}$, Mount Caroline; MtSt, Mount Stirling. Note that E. caesia subsp. magna is monophyletic and subsp. caesia is paraphyletic. 
Using morphological and allozyme data, scored as both continuous and binary variables, Hopper \& Burgman (1983) carried out phenetic and cladistic analyses of 11 populations representing both subspecies of E. caesia, with E. crucis subsp. lanceolata as the outgroup for the cladistic analyses. Their best estimate of phylogeny, derived by combining allozyme frequencies and morphometric data (Hopper \& Burgman 1983: fig. 3), showed subsp. magna to be monophyletic and nested deeply within subsp. caesia (Fig. 4). Subsp. caesia is paraphyletic, because subsp. magna is derived from an ancestral population of subsp. caesia (Hopper \& Burgman 1983: 47). Therefore, the distinguishing features listed above should be interpreted as autapomorphies for subsp. magna. The authors of this study appeared quite comfortable with their conclusion that a recognised taxon (E. caesia subsp. caesia) was shown to be paraphyletic, and did not suggest any taxonomic rearrangement.

\section{Eucalyptus baxteri group}

The stringybark eucalypts are a monophyletic group restricted to mainland eastern Australia and characterised by an apomorphic bark type as well as distinctive hairs radiating from raised oil glands on the seedling leaves (Brooker \& Kleinig 1983; Ladiges \& Humphries 1986). In a cladistic analysis of the group using morphology of seedlings and adults, Ladiges and Humphries (1986) found a clade comprising E. deuaensis, $E$. baxteri and E. alpina. For the purpose of analysis, they recognised two forms within E. baxteri (South Australian and Victorian) and two within E. alpina (Mirranatwa Gap and Victoria Range). In their phylogeny, E. alpina was monophyletic but E. baxteri was paraphyletic, with the South Australian form sister-taxon to the Victorian form plus E. alpina. Morphometric studies on populations of E. baxteri (Marginson \& Ladiges 1988) found two distinct phenetic clusters corresponding with the above geographic forms, which were treated as two species: E. baxteri sens. str. and E. arenacea, sp. nov. However, no morphological autapomorphy was discovered for either segregate species. Subsequently, Whiffin \& Ladiges (1992) investigated variation in leaf volatile oils among populations of E. arenacea, E. baxteri sens. str. and E. alpina, using phenetics and cladistics based on distance data (leaf volatile oil composition cannot be expressed as discrete quantitative characters). Their sampling of populations of E. alpina was more comprehensive than in the previous studies. Although they obtained different phylogenies depending upon the tree-building method, all agreed that E. arenacea is monophyletic, whilst both E. baxteri sens. str. and E. alpina are paraphyletic (Fig. 5). Eucalyptus alpina was found to comprise three distinct (autapomorphic?), allopatric forms appearing to originate independently, either from within E. baxteri, or sharing a common ancestor with E. baxteri (Fig. 5). Each was described as a species (Ladiges \& Whiffin 1993). This pattern, consisting of several distinctive, apparently autapomorphic species nested within a widespread, variable paraphyletic species is very similar to that shown by Daviesia ulicifolia (above). These authors did not explicitly discuss the consequences of knowingly circumscribing E. baxteri as a paraphyletic species, although to be fair they did not change its status - it had always been paraphyletic.

\section{Corallorhiza maculata}

In a detailed and comprehensive study, Freudenstein \& Doyle (1994) constructed a well-corroborated phylogeny of 35 populations of Corallorhiza maculata (Orchidaceae) and two closely related species using restriction fragment variation of plastid DNA. All three species were recognised under the phylogenetic species concept because they were diagnosable by morphological characters. Plastome types corroborated these diagnoses. The plastid phylogeny showed $C$. maculata to be paraphyletic because both other species were nested within it. Acknowledging this, the authors were nevertheless prepared to recognise all three species. 


\section{Helianthus petiolaris}

Using restriction fragment polymorphisms of nuclear and chloroplast DNA, Rieseberg and Brouillet (1994) constructed a phylogeny of populations representing Helianthus neglectus (Asteraceae: Astereae) and two subspecies of $H$. petiolaris. Helianthus annuus was used as the outgroup. This phylogeny showed $H$. neglectus as a metaspecies, $H$. petiolaris subsp. fallax as paraphyletic with respect to $H$. neglectus, and $H$. petiolaris subsp. petiolaris as paraphyletic with respect to both subsp. fallax and H. neglectus (Fig. 6). Not too much should be made of their result because only four characterstate changes occur on a tree with 12 terminal taxa. Additional informative characters may well produce a different topology.

\section{Examples of metaspecies}

Phylogenetic analyses at the level of populations, as decribed above, are uncommon. In the absence of a broad-based sample of such studies, we have no reliable estimate of the overall frequency of paraphyletic species. An indirect estimate may be gained from the lack of identified autapomorphies in terminal taxa (species and subspecies) which have been included in cladistic analyses. A taxon lacking an autapomorphy is potentially paraphyletic, a 'metaspecies' (Donoghue 1985; de Queiroz \& Donoghue 1988). This simpler approach allows the possibility of using large samples. However, it is restricted to taxa for which there are phylogenies using species as terminal taxa. In the absence of a phylogeny there is no basis for judging whether a character fixed in a species is an autapomorphy or a retained plesiomorphy.

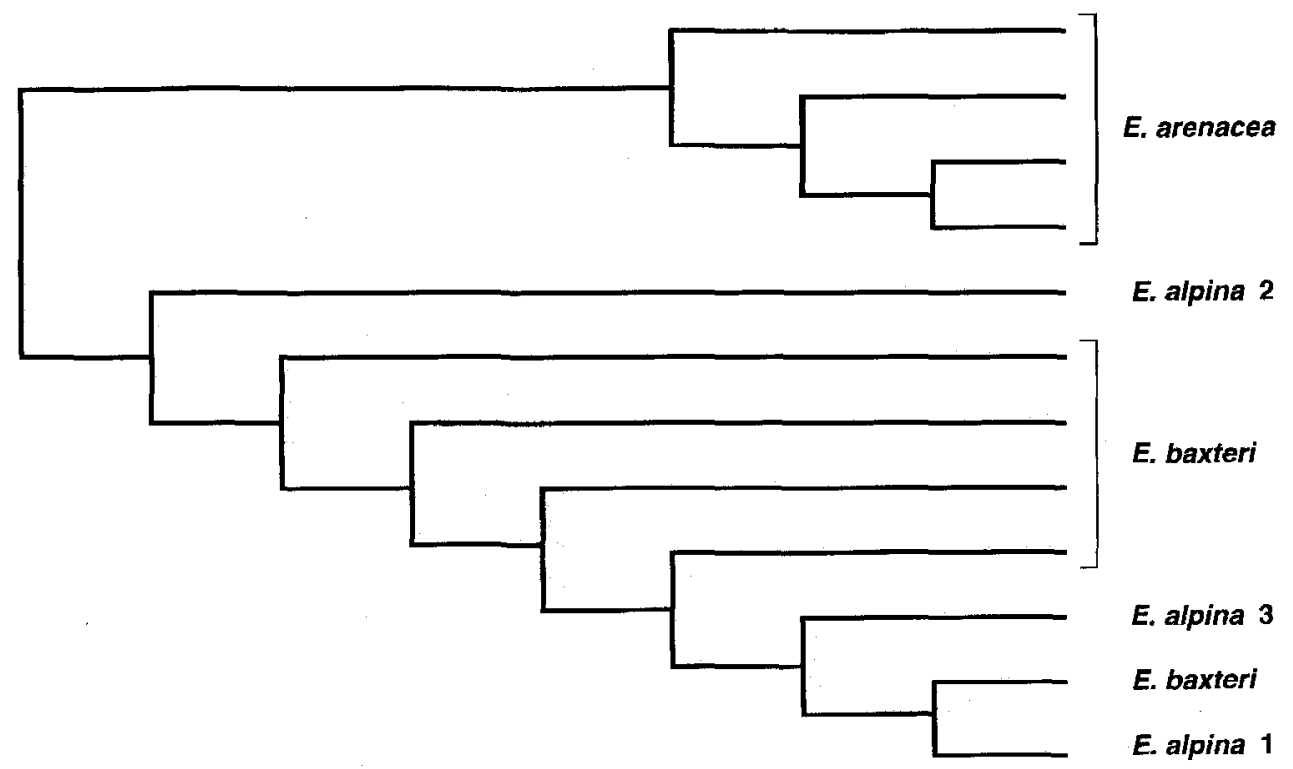

Fig. 5. Phylogeny of populations of Eucalyptus baxteri, E. arenacea and E. alpina, based on leaf volatile oil composition and derived using distance Wagner with Manhattan distance (Whiffin \& Ladiges 1992: Figs 8a and 9a combined). E. arenacea is monophyletic, and both E. baxteri and E. alpina are paraphyletic. 
Estimating paraphyly from absence of autapomorphy is subject to the following sources of error. First, a metaspecies may have a cryptic autapomorphy which remains undiscovered. In other words, a metaspecies is also potentially monophyletic. This will lead to overestimation of the number of paraphyletic taxa. Second, a feature that appears to be an autapomorphy in a species treated as an undivided taxon may prove to be homoplastic when cladistic analysis is done at a lower level.

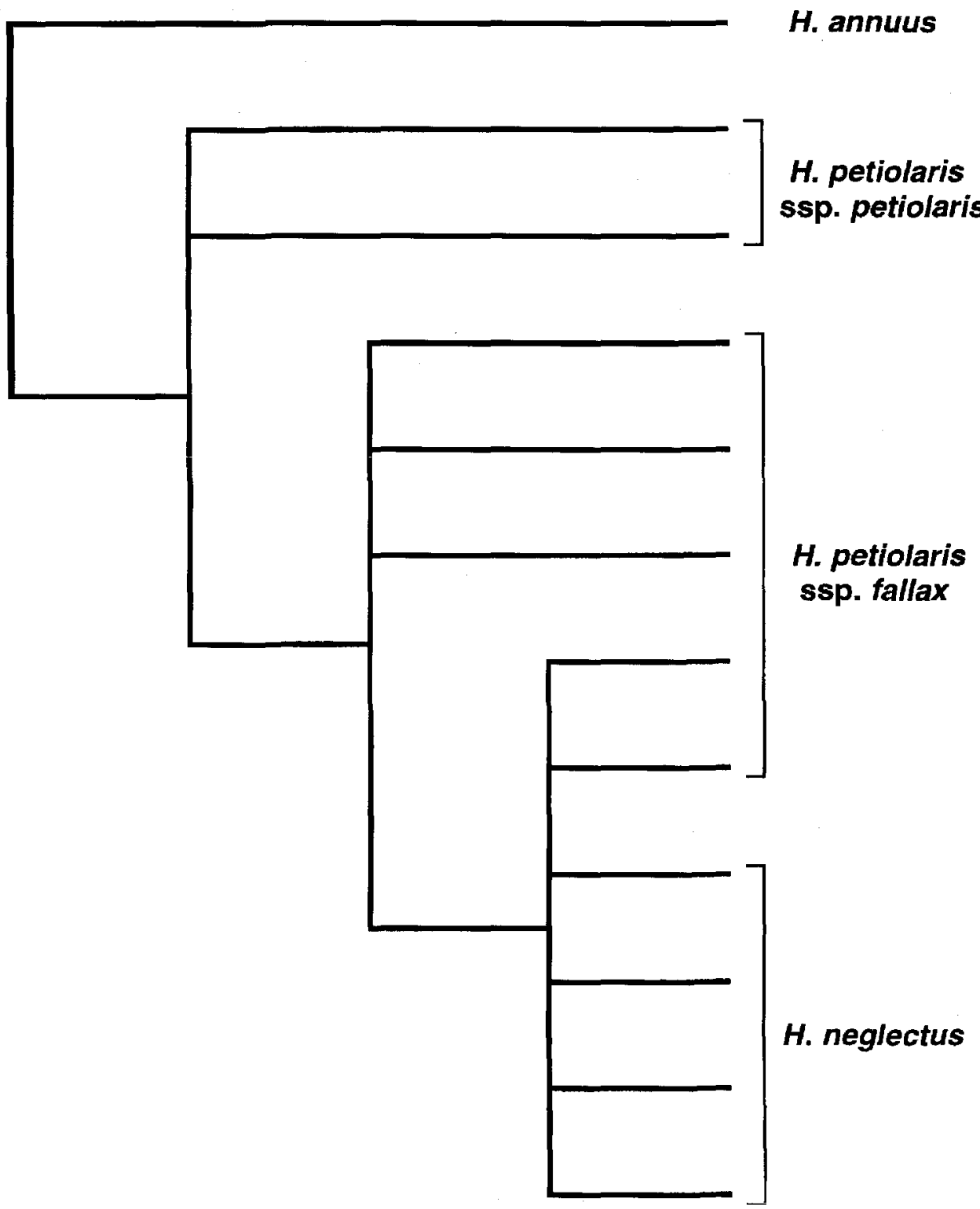

Fig. 6. Phylogeny of populations of Helianthus petiolaris and H. neglectus (Rieseberg et al. 1991; Rieseberg \& Brouillet 1994). This is the most parsimonious tree derived from chloroplast and nuclear ribosomal DNA restriction site polymorphisms (consistency index $=1$ ). Outgroup is $H$. annuus. Note that $H$. neglectus is metaphyletic, $H$. petiolaris and its subsp. fallax are both paraphyletic, and $H$. petiolaris subsp. petiolaris is metaphyletic. 
For example, trigonous leaves appear to be an autapomorphy for Daviesia ulicifolia when it is assumed to be monophyletic as traditionally circumscribed (above). However, cladistic analysis using geographic forms as terminals nests three recognised species within $D$. ulicifolia: $D$. acicularis, $D$. arenaria and $D$. microcarpa. None of these has trigonous leaves, so the character shows three homoplastic changes within the D. ulicifolia clade, and D. ulicifolia is shown to be paraphyletic. These two sources of error have opposite effects, respectively overestimation and underestimation of the number of paraphyletic species, although this is not to say that they will cancel out one another.

With these caveats in mind, we have tabulated all known species and subspecies (206) from eight genera in two distantly related families (Appendix 1). These are Brachysema, Chorizema and Daviesia (Fabaceae) and Alloxylon, Embothrium, Lomatia, Oreocallis and Telopea (Proteaceae). All have been subject to recent taxonomic revision and cladistic analysis at species level (Pate et al. 1989; Crisp 1990; Crisp 1991; Taylor \& Crisp 1992; Weston \& Crisp 1994; Crisp 1995a; Crisp 1995b; Crisp \& Weston 1995). In this sample, methodological bias between taxonomic workers is minimised because all treatments involve Crisp as an author. Appendix 1 lists the hypothesized autapomorphies for every species and subspecies. Where a taxon appears to lack an autapomorphy, we have listed its putative sister-group(s) whose formal recognition may render the metataxon paraphyletic. These data are summarised in Table 4.

Telopea speciosissima (Proteaceae) is a good example of a metaspecies from Appendix 1. As originally circumscribed, it possessed obvious autapomorphies in the enlarged, bright red involucral bracts of the conflorescence (see the cover of this journal), as well as toothed leaves, raised venation and pollen sculpturing. However, with the segregation of $T$. aspera on the basis of its autapomorphic harsh texture and rusty indumentum of the leaves (Crisp \& Weston 1993; Crisp \& Weston 1995), the autapomorphies of the old $T$. speciosissima became synapomorphies for a monophyletic group comprising both species (Weston \& Crisp 1994). In its newer, restricted circumscription, T. speciosissima lacks an evident autapomorphy. Moreover, those populations of $T$. speciosissima which are geographically closest to $T$. aspera have a low density of rusty hairs on the leaves (Crisp \& Weston 1993), and thus may be more closely related to $T$. aspera than to more distant populations of $T$. speciosissima. This hypothesis, though plausible, should be tested by cladistic analysis at the population level before $T$. speciosissima can be declared paraphyletic with confidence. Until then it should be considered a metaspecies.

Within the same genus, $T$. oreades may also be paraphyletic. Its sister taxon is $T$. mongaensis, which has an autapomorphic absence of leaf sclereids (Weston \& Crisp 1994). Absence of lobing in the early intermediate leaves is an apparent autapomorphy for T. oreades; however, this feature is very homoplastic within the subtribe Embothriinae (Weston \& Crisp 1994) and recent morphometric studies have revealed a sporadic occurrence of lobes in some populations of T. oreades (Parrish \& Crisp, unpublished). The geographic distribution of $T$. oreades populations also suggests paraphyly. Most populations occur in the east Gippsland region of Victoria; however, one highly disjunct population occurs sympatrically with the southernmost population of T. mongaensis, in New South Wales (Crisp \& Weston 1987; Crisp \& Weston 1993). In the area of sympatry, morphometric and molecular (RAPD) evidence indicate hybridization between the two species, and this site falls outside the main bioclimatic envelope of $T$. oreades (Parrish \& Crisp, unpublished). Thus it seems likely that the disjunct population is more closely related to T. mongaensis than to the Gippsland populations of $T$. oreades, in which case, $T$. oreades would be paraphyletic. This hypothesis is currently being tested by molecular phylogenetic analysis of populations (Parrish \& Crisp, unpublished). 
Within the Fabaceae, both Daviesia mimosoides and D. buxifolia have been recognised by taxonomists for more than a century (Crisp 1991; Crisp 1995a). Whilst D. buxifolia has apparent autapomorphies in the crenulate, cordate leaves, $D$. mimosoides has no evident autapomorphy. Recently, on the basis of phenetic analysis, Crisp (1991) recognised a montane autapomorphic subspecies (acris) within $D$. mimosoides and segregated a metaspecies (D. elliptica) from D. mimosoides and D. buxifolia. All these taxa are well-defined clusters in morphometric space. Cladistic analysis of the whole D. latifolia group, including these phenetic taxa as terminals (Crisp 1991), shows the two subspecies of $D$. mimosoides to be the unresolved sister-group to a clade comprising $D$. buxifolia and $D$. elliptica. Thus, D.mimosoides may be paraphyletic with respect to $D$. buxifolia and D. elliptica, D. elliptica may be paraphyletic with respect to D. buxifolia, and $D$. mimosoides subsp. mimosoides may be paraphyletic with respect to subsp. acris.

Overall, $21 \%$ of the species and subspecies examined lack autapomorphies and thus may be paraphyletic (Table 4). This reflects the proportion in the Fabaceae but the proportion of Proteaceae is greater (33\%). However, as the Proteaceae sample is small $(n=24)$, not much should be made of this difference. Among genera, the proportion ranges from $0 \%$ (Embothrium) to $50 \%$ (Oreocallis) but these extremes may reflect sampling error because they are the smallest genera ( 1 and 2 species respectively). More interesting is the difference between species (17\%) and subspecies $(50 \%)$, which a G-statistic test (Sokal \& Rohlf 1981) shows to be significant $(G=12.268,1$ d.f., $\mathrm{P}<0.001)$. This result is unsurprising, because at the lower taxonomic level (subspecies), taxa are less likely to be fully differentiated, autapomorphic lineages. We have also tabulated a geographic

Table 4. Summary of metataxa (species and subspecies lacking evident autapomorphies) in some genera from Proteaceae (tribe Embothrieae) and Fabaceae (tribe Mirbelieae) for which phylogenies are available. Tribal subtotals reflect only the genera listed in this table. In the last line of the table, 'other' includes central Australia, northern Australia and other parts of the world. For a full listing of taxa and their autapomorphies, see Appendix 1.

\begin{tabular}{|c|c|c|c|c|}
\hline Taxon & $\begin{array}{l}\text { Total } \\
\text { taxa }\end{array}$ & $\begin{array}{l}\text { With autapomorphies } \\
\text { (monophyletic) }\end{array}$ & $\begin{array}{l}\text { No autapomorphy } \\
\text { (metataxa) }\end{array}$ & $\begin{array}{l}\text { Metataxa } \\
\text { (\%) }\end{array}$ \\
\hline \multicolumn{5}{|c|}{ Proteaceae: Embothrieae } \\
\hline Alloxylon & 4 & 3 & 1 & 25 \\
\hline Embothrium & 1 & 1 & 0 & 0 \\
\hline Lomatia & 12 & 8 & 4 & 33 \\
\hline Oreocallis & 2 & 1 & 1 & 50 \\
\hline Telopea & 5 & 3 & 2 & 40 \\
\hline Subtotal & 24 & 16 & 8 & 33 \\
\hline \multicolumn{5}{|c|}{ Fabaceae: Mirbelieae } \\
\hline Brachysema & 10 & 7 & 3 & 30 \\
\hline Chorizema & 27 & 25 & 2 & 7 \\
\hline Daviesia & 145 & 114 & 31 & 21 \\
\hline Subtotal & 182 & 146 & 36 & 20 \\
\hline Total (all taxa) & 206 & 162 & 44 & 21 \\
\hline Species & 180 & 149 & 31 & 17 \\
\hline Subspecies & 26 & 13 & 13 & 50 \\
\hline Eastern Australia & 51 & 33 & 18 & 35 \\
\hline Western Australia & 143 & 120 & 23 & 16 \\
\hline Other & 12 & 9 & 3 & 25 \\
\hline
\end{tabular}


comparison between eastern Australia and western Australia, excluding the central arid region and central-northern monsoonal region ('Top End'). Thus the comparison is between the humid and subhumid south-west on the one hand, and the humid and subhumid east coast and ranges on the other. These regions were divided by onset of aridity during the late Miocene-Pliocene, particularly the formation of the Nullarbor Plain. Interestingly, the proportion of metataxa in the west $(16 \%)$ is less than half that in the east (35\%). This difference is significant $(G=7.736,1$ d.f., $P<0.01$ ), and suggests that the history of speciation or subsequent differentiation has differed in the two regions.

\section{Discussion}

\section{Species concepts predict paraphyly}

The examples given in this paper represent a common (perhaps universal) pattern of asymmetry between sister species. Hennig (1966: 59) recognised this asymmetry, and described it as the 'deviation rule'. A divergent, autapomorphic species is either sister taxon to a metataxon, or nested within a paraspecies. In this view, branch-points in phylogenetic trees are like a bush of twigs (metataxa) from which leaders (autapomorphic taxa) emerge (cf. de Queiroz \& Donoghue 1990a: fig. 6). In fact, virtually all concepts that treat species as historical entities make an implicit or explicit prediction that some or all species are not monophyletic. Evolutionary and related species concepts (Wiley 1981; Frost \& Kluge 1995) treat permanently split lineages as species. It is not surprising that proponents of the lineage notion of species are preoccupied with exclusivity (de Queiroz \& Donoghue 1988; de Queiroz \& Donoghue 1990a; de Queiroz \& Donoghue 1990b; Baum \& Shaw 1995; Graybeal 1995) because all newly established lineages probably are not exclusive (sensu Donoghue 1985), and thus either paraphyletic, metaphyletic, or even polyphyletic if reticulation continues (cf. Frost \& Kluge 1995: fig. 3). The expectation is that they eventually become exclusive (by extinction of part of the paraphyletic or metaphyletic residue) and monophyletic (by acquiring new autapomorphies) (Rieseberg \& Brouillet 1994; Baum \& Shaw 1995; Frost \& Kluge 1995; Graybeal 1995), but the prediction of initial non-monophyly discomfits many authors. Frost \& Kluge (1995) reject exclusivity arguments as invalid reductionism from one 'scalar' level of explanation (species) to another (populations or individuals). However, to us it seems a logical extension to analyse species at the level of their subunits, such as populations or internodons (Kornet 1993a). To regard species as indivisible seems absurd.

Under the phylogenetic species concept, any species that is diagnosed by at least one autapomorphy is expected to be monophyletic, but any species that is diagnosed only by plesiomorphies may be either metaphyletic or paraphyletic. The composite species concept goes further: it explicitly predicts that all species are paraphyletic groups of their subunits (internodons), unless they have spawned no descendant species (Kornet 1993b: fig. 5a). Moreover, Kornet's model predicts that most species give rise to descendant species, except a few that become extinct before they can do so. This is because composite species are viewed as branches from a main limb, rather than equally splitting branches, emphasizing the same asymmetry at speciation as recognised in Hennig's deviation rule (Kornet 1993a: 87).

Only the monophyletic (autapomorphic) species concept disallows the possibility of non-monophyletic species, but at a high cost. Either species would not be mutually exclusive and ancestral species would include descendant species (Kornet 1993b: 71), or it would be necessary to reject all species that lack autapomorphies, which would leave many organisms permanently unassigned to species. Both alternatives would be unacceptable to most biologists. 


\section{Asymmetric speciation}

Commonly hypothesized modes of speciation are allopatric, sympatric and peripheral isolation (Mayr 1982; Lynch 1989; Rieseberg et al. 1991; Theriot 1992). Allopatric speciation, in which a widespread ancestral species is split into vicariant (geographically isolated) populations which then differentiate and speciate, seems more likely to be symmetric, resulting in a pair of autapomorphic species. This is the speciation model usually assumed as a basis for cladistic vicariance biogeography (Nelson \& Platnick 1981; Humphries \& Parenti 1986; Cracraft 1989). However, sympatric speciation and peripheral isolation seem likely to result in the two daughter species that have populations very unequal in size. Lynch (1989) uses the admittedly arbitrary rule that if one species has a distributional area no more than $5 \%$ of its sister, this represents peripheral isolation rather than vicariance (allopatry). Similarly, local (sympatric) ecological differentiation and speciation of a small population under strong selection (Andersson 1990; Rohwer \& Kubitzki 1993; Linder 1995) should also result in asymmetry.

Thus some modes of speciation involve isolation of a small population. This may differentiate rapidly and evolve fixed differences from the parental population (autapomorphies) through processes such as founder effect, bottlenecks, genetic drift, selection and lineage sorting (Eldredge \& Cracraft 1980; Wiley 1981; Rieseberg \& Brouillet 1994). The much larger parental populations would be buffered against these effects, and so may persist for a long period without diverging from their ancestral condition. If the ancestral species were widespread, and had already fragmented into isolated, partly divergent populations, then the peripherally speciating population may be historically more closely related to an adjacent population than to other, more distant populations. In other words, the parental species would be paraphyletic.

But is allopatric speciation necessarily symmetrical? If two relatively large populations become isolated from one another, divergence is likely to be gradual, and fixation of novel characters probably would occur some time after isolation. Thus some authors (Nixon \& Wheeler 1992; Patton \& Smith 1994; Rieseberg \& Brouillet 1994) have suggested that species start out as a metaphyletic or paraphyletic group of populations (or even polyphyletic, due to reticulation) and only gradually become monophyletic (cf. Frost \& Kluge 1995: fig. 3). Therefore, through any mode of speciation, whether symmetrical or not, either one or both daughter species is likely to appear at least temporarily non-monophyletic.

\section{Species concepts: a solution to the conundrum}

If species are no different from higher taxa (except in rank), and if taxa are forbidden to be paraphyletic or metaphyletic, then there is a paradox, because we have shown above that many species are unavoidably paraphyletic or metaphyletic. One solution would be to adopt the monophyletic species concept, and treat only demonstrably monophyletic species as taxa. Thus Donoghue (1985) and de Queiroz \& Donoghue (1988) suggested marking metaspecies with an asterisk to identify them as different in kind from monophyletic species. This is tantamount to excluding paraphyletic and metaphyletic populations from species. Instead they would sit as unassigned residual populations at the base of higher (monophyletic) taxa. This treatment seems unacceptable to most systematists. It is clear that the great majority prefer to treat species as taxa, being part of the system to which all higher taxa belong. Therefore the only reasonable alternative is to drop the monophyly requirement for species. In other words, species may be considered taxa but with the special provision that they may be paraphyletic or metaphyletic. Is there a logical basis for defining species as special taxa? There would be if species had a property that made them different 
from higher taxa. Such a property exists: it is their position at the base of the phylogenetic system. All higher taxa consist of at least two terminals (species) which share one or more apomorphies. (Monotypic higher taxa have only one species, which should have an autapomorphy.) However species, being basal in the system, are the generators of apomorphies. If speciation is the point at which apomorphies appear (= fixation of a new character), then this event irreversibly transforms the ancestral species from an autapomorphic (monophyletic) entity to a symplesiomorphic (metaphyletic) one. If species are the generators of new species, then they cannot be simultaneously monophyletic. Species are temporarily monophyletic if they have not yet spawned a daughter species. They are permanently monophyletic only if they have become extinct without leaving a descendant. A corollary of this special view of species is the notion that when species are conceived as part of lineages, speciation is not coincident with the splitting of lineages. It is the point at which autapomorphies evolve. Thus the appropriate model of speciation is an asymmetric one of branching off, not a symmetric one of splitting (Kornet 1993b).

\section{How frequent are paraphyletic species?}

From the discussion above it is clear that most species concepts predict a high frequency of paraspecies and metaspecies (except the monophyletic species concept, which evades the problem). Suppose that we segregate as a species any autapomorphic set of populations and segregate as another species the set of populations that is diagnosed only by lacking the autapomorphy. This procedure would be consistent with both the phylogenetic species concept and the composite species concept. It reflects the asymmetric model of speciation presented above. Both species are uniquely diagnosable but the first species would be monophyletic and the second either paraphyletic or metaphyletic. If this simple protocol worked in all cases, at least $50 \%$ of all species would be either paraphyletic or metaphyletic.

However it is possible that two diagnosable sister-groups would each show a (different) autapomorphy. Both would be treated as species and both would be monophyletic. Such occurrences would lower the overall proportion of nonmonophyletic species. This scenario does not require symmetrical splitting of lineages, since it may be assumed that there is some delay between lineage splitting and character fixation (Nixon \& Wheeler 1992; Kornet 1993b). If this delay is very different in the two daughter lineages, then observation of both at the same time is likely to show one species to be autapomorphic and its sister group to be metaphyletic. However, even if there is such a difference, both lineages may be sufficiently old to have acquired an autapomorphy (i.e., speciated) when observed. (This assumes that neither lineage has split again in the meantime.) Thus the frequency of symmetrical versus asymmetrical speciation will depend partly on the probability of lineages splitting, relative to the probability of character fixation. If this ratio were high, then speciation would appear asymmetrical in most cases, and the proportion of nonmonophyletic species could be well above $50 \%$. If the ratio were low, then autapomorphic species pairs would be more common and the proportion of nonmonophyletic species would lie closer to $0 \%$. Note that if two allopatric populations have split permanently (cf. evolutionary species concept) but neither has yet acquired an autapomorphy, then we have no evidence for treating them as distinct species. For this reason, we would never expect $100 \%$ non-monophyletic species.

In this paper we have presented several empirical examples of paraspecies and metaspecies. All these examples are plants, but animal examples arising from phylogenetic analysis at the population level exist too (Green \& Borkin 1993; Melnick \& Hoelzer 1993; Melnick et al. 1993; Hoelzer \& Melnick 1994; Patton \& Smith 1994). However, these are selected examples and give no clue to the frequency of non- 
monophyletic species. Based on the frequency of metaspecies lacking evident autapomorphies, they may comprise a high proportion of all recognised species. Our partial survey of two angiosperm families suggests that $21 \%$ of species and subspecies are potentially paraphyletic. From a broad survey of speciation patterns in animals, Lynch (1989) concludes that $21 \%$ of animal species arose by either sympatric speciation or peripheral isolation, and thus are likely to have a complementary paraspecies (above). Ackery \& Vane-Wright (1984) estimate the proportion of paraspecies to be $50 \%$ in the milkweed butterflies. All these estimates fall within the theoretical range (above), so are plausible.

\section{Biogeographic differences}

The empirical difference in the proportion of metaspecies between eastern (35\%) and western (16\%) Australia is intriguing, because it reflects variation within higher taxa that are common to both regions. Interspecific hybrids also appear to be more common in the east than in the west, e.g. within Daviesia (Crisp 1991). Perhaps both patterns are related to the same cause: a historical difference in mode of speciation in the two regions. By definition, a metaphyletic species has not diverged in morphology from its nearest ancestor. Therefore there is a good chance that it has not diverged reproductively from its relatives either, and it may be more likely to hybridise than a highly autapomorphic species. Further research should investigate what biogeographic differences may underly these east-west contrasts.

\section{Are paraphyletic species avoidable?}

Some cladists go out of their way to avoid recognising non-monophyletic taxa, even at species level. For instance, Thiele \& Ladiges (1994) refrained from segregating the autapomorphic taxon aquilonia from Banksia integrifolia on the implicit grounds that the residual $B$. integrifolia would be paraphyletic (confirmed by K.R. Thiele, pers. comm.). Instead, they treated aquilonia as a subspecies, but this action probably only regressed the problem to a lower rank, that of subspecies. The remaining subspecies of $B$. integrifolia (compar, integrifolia and monticola) are not as distinct as aquilonia, and appear to be metaphyletic. This manner of avoiding paraphyletic species by regress does not solve the problem; it merely pushes it back to a lower rank. Another way of avoiding paraphyletic species would be not to recognise any taxon that leaves a paraphyletic residual. For example, no taxa might be recognised within $B$. integrifolia sensu lato, not even the autapomorphic aquilonia. However, this solution is unrealistic and unreasonable. Any well-corroborated, monophyletic taxon is worthy of formal recognition and sooner or later will be recognised.

Some authors have suggested that paraphyletic taxa are an artifact of the Linnean system, because it prescribes mandatory categories (de Queiroz \& Gauthier 1990; de Queiroz \& Gauthier 1992). Under the rules of nomenclature, all organisms must be assigned to a species, genus and family. Therefore when a new family, genus or species is segregated from a taxon of the same rank, the rules require that the residual group be formally named at that rank too. If the segregant taxon is autapomorphic (i.e., monophyletic), then the residual is likely to be symplesiomorphic (i.e., paraphyletic). For example, the segregation of three autapomorphic species from the old Eucalyptus alpina (above) leaves a paraphyletic group of populations that must take a species name (in this case, E. baxteri). At higher ranks, say genus, the problem can be solved by splitting the residual group further into monophyletic taxa, each of which is named as a genus. However, at species level this solution is not possible - there are unlikely to be monophyletic groups within the residual. But even without the mandatory Linnean categories, paraphyletic taxa would be 
created. Like Linnaeus, most taxonomists want to put organisms in pigeon holes. Complementary (paraphyletic) groups at all ranks have always been treated as taxa and continue to be spoken of, even by cladists, e.g. gymnosperms, dicots, algae, reptiles, dinosaurs, amphibians, fish.

Returning to species, we conclude that there is not a problem with the recognition of paraphyletic and metaphyletic species. Problems arise only because some systematists want an all-inclusive concept of taxa that will allow all organisms to be assigned to a species using the same criteria as for higher taxa. However both theory and the discovered pattern of relationships among organisms show that no such universal criterion is possible. Species are different from higher taxa because they are basal, so a special criterion is justified. Paraphyletic and metaphyletic species are theoretically unavoidable, unless the autapomorphic species concept is adopted, in which case the problem is merely swept under the carpet. As we have concluded above, the appropriate species concept in a phylogenetic system is either the phylogenetic species concept or the related composite species concept. Both predict that some species will be monophyletic and others paraphyletic or metaphyletic.

\section{Implications for historical applications}

One of the arguments against recognising paraphyletic taxa is that they may be used in other biological applications with the assumption that they are monophyletic, e.g. Cracraft (1989). If the assumption of monophyly is invalid, does this invalidate the application? Let us consider cladistic biogeography.

Cladistic biogeogeography attempts to discover historical patterns of areas manifest by congruence among the phylogenies of different taxa occurring in the same areas. Because of confounding factors such as failure of some taxa to speciate when areas differentiate, extinction, incomplete sampling and dispersal, some methodological rules are necessary. Component analysis (Nelson \& Platnick 1981; Humphries \& Parenti 1986; Page 1990) uses three 'assumptions' incorporating different rules (Nelson \& Platnick 1981; Zandee \& Roos 1987). For example, Assumption 0 treats widespread species (Fig. 7a) as if they (and the areas in which they occur) were monophyletic. If the species in question (and the history of the combined areas in which it occurred) were actually paraphyletic (Fig. 7a), this assumption would fail to reconstruct the area-phylogeny (Fig. 7c). Assumption 0 is inappropriate if a paraphyletic taxon occupies multiple areas because its ancestor failed to differentiate when the areas differentiated (Page 1989: 169). The more relaxed Assumption 1 treats widespread areas as either monophyletic or paraphyletic. Congruence with a well-corroborated pattern shown by another group with a monophyletic taxon in each area would then favour the well-corroborated solution (Fig. 7e), rather than a misleading one (Figs. 7c-d). Assumption 2, which considers possible polyphyly of areas, would also support the well-corroborated pattern. Therefore in this example at least, a paraphyletic species would not seriously mislead cladistic biogeography, at least under Assumptions 1 and 2. Rage \& Jaeger (1995) argue that paraphyletic taxa can be used meaningfully in biogeography, the only deficiency being the information that is missing because part of the taxon has been excluded taxonomically.

In simulations of macroevolution, Sepkoski \& Kendrick (1993) found that paraphyletic taxa treated as if monophyletic did not seriously mislead estimation of speciation and extinction rates, except when sampling was poor. Smith (1994b: 88-91) states that paraphyletic taxa can be used validly in estimating patterns of taxon origination and standing species-level ['phenon-level'] diversity, but not extinction patterns. The latter restriction applies because paraphyletic taxa may disappear from the fossil record due to pseudoextinction, when a member of the paraphyletic group gives rise to an autapomorphic descendant taxon. 

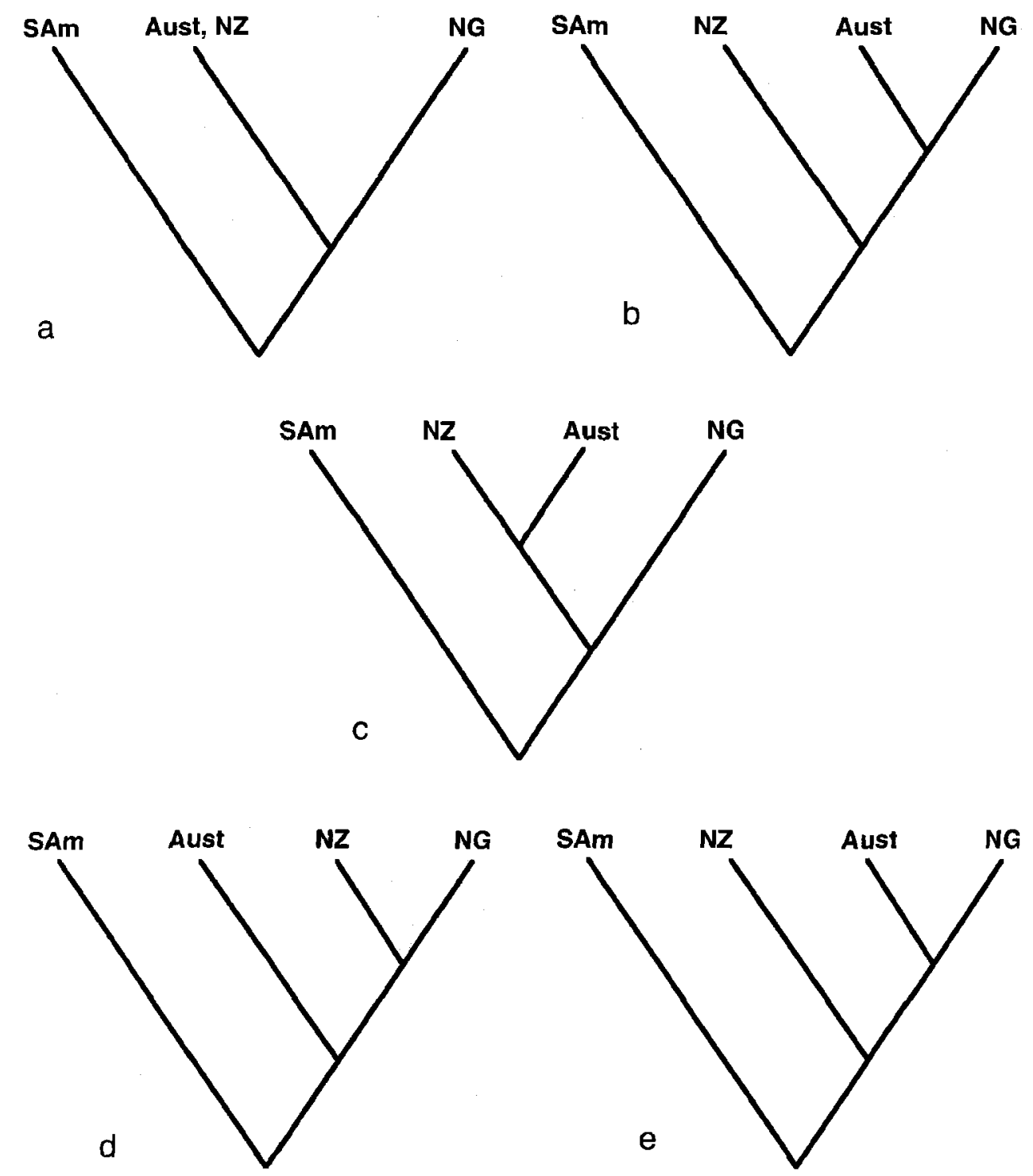

Fig. 7. Retrieving biogeographic pattern using a paraphyletic species. a, An unreduced areacladogram derived from a taxon-cladogram with a paraphyletic species which is widespread in Australia (Aust) and New Zealand (NZ), a monophyletic species restricted to South America (SAm) and another monophyletic species which is restricted to New Guinea (NG). b, A wellcorroborated estimate of the phylogeny of these areas, derived from the phylogeny of another taxon. c, Assumption 0, which assumes all taxa to be monophyletic, would retrieve this area cladogram from that in $7 \mathrm{a}$. It conflicts with that in $7 \mathrm{~b}$. d-e, Both these area-cladograms (and that in $7 \mathrm{c}$ ) would be allowed by Assumption 1; $\mathbf{e}$ is congruent with the cladogram in $7 \mathrm{~b}$, and would be favoured as a general area-cladogram. Assumption 2 would allow either (SAm,(Aust,NG)) or $(\mathrm{SAm},(\mathrm{NZ}, \mathrm{NG})$ ). Both are combinable with $7 \mathrm{~b}$, which again would be the favoured solution. 
We are sure that other examples can be constructed in which paraphyletic taxa would positively mislead an application in comparative biology, if they were falsely assumed to be monophyletic. However in many cases, such as the biogeographic example above, the problem may be no greater than the addition of a degree of uncertainty. More attention should be given to the influence of paraphyletic species to such analyses, because inevitably and unwittingly, paraphyletic species are being used as if they were monophyletic.

\section{Acknowledgements}

We wish to thank the Coopers and Cladistics discussion group for many stimulating arguments over the nature of species. Belinda Alvarez de Glasby, Peter Cranston, Dan Faith, Chris Glasby, Penny Gullan, Peter Linder, Peter Weston, an anonymous referee and the Telopea editorial committee provided useful comments on the manuscript.

\section{References}

Ackery, P.R. \& Vane-Wright, R.I. (1984) Milkweed Butterflies: Their Cladistics and Biology (Cornell University Press: Ithaca, New York).

Andersson, L. (1990) The driving force: species concepts and ecology. Taxon 39: 375-382.

Arnold, M.L. (1992) Natural hybridization as an evolutionary process. Annual Review of Ecology and Systematics 23: 237-261.

Barton, N.H. \& Hewitt, G.M. (1989) Adaptation, speciation and hybrid zones. Nature 341: 497-503.

Baum, D. (1992) Phylogenetic species concepts. Trends in Ecology and Evolution 7: 1-2.

Baum, D. \& Shaw, K.L. (1995) Genealogical perspectives on the species problem. Pp. 289-303 in P.C. Hoch \& A.G. Stephenson (ed.), Monographs in Systematic Botany from the Missouri Botanical Garden, vol. 53 (Missouri Botanical Garden: St Louis).

Bentham, G. (1864) Flora Australiensis (Reeve \& Co.: London).

Brooker, M.I.H. \& Hopper, S.D. (1982) New subspecies in Eucalyptus caesia and in E. crucis (Myrtaceae) of Western Australia. Nuytsia 4: 113-128.

Brooker, M.I.H. \& Kleinig, D.A. (1983) Field Guide to Eucalypts. Volume 1. South-eastern Australia (Inkata Press: Melbourne and Sydney).

Brooker, M.I.H. \& Kleinig, D.A. (1990) Field Guide to Eucalypts. Volume 2. South-Western and Southern Australia (Inkata Press: Melbourne and Sydney).

Cracraft, J. (1989) Speciation and its ontology: the empirical consequences of alternative species concepts for understanding patterns and processes of differentiation. Pp. 28-59 in D. Otte \& J.A. Endler (ed.), Speciation and its Consequences (Sinauer Associates: Sunderland).

Crisp, M.D. (1990) Contributions towards a revision of Daviesia (Fabaceae: Mirbelieae): I. The D. squarrosa group. Australian Systematic Botany 3: 241-251.

Crisp, M.D. (1991) Contributions towards a revision of Daviesia Smith (Fabaceae: Mirbelieae). II. The D. latifolia group. Australian Systematic Botany 4: 229-298.

Crisp, M.D. (1995a) Contributions towards a revision of Daviesia (Fabaceae: Mirbelieae). III. A synopsis of the genus. Australian Systematic Botany 8: 1155-1249.

Crisp, M.D. (1995b) Revision of Brachysema (Fabaceae: Mirbelieae). Australian Systematic Botany 8: 307-353.

Crisp, M.D. \& Weston, P.H. (1987) Waratahs - how many species? Pp. 3-15 in J.A. Armstrong (ed.), Waratahs, their Biology Cultivation and Conservation (Australian National Botanic Gardens: Canberra).

Crisp, M.D. \& Weston, P.H. (1993) Geographic and ontogenetic variation in morphology of Australian waratahs (Telopea: Proteaceae). Systematic Biology 42: 49-76.

Crisp, M.D. \& Weston, P.H. (1995) Alloxylon and Telopea (Proteaceae). Pp. 383-390 in P. McCarthy (ed.), Flora of Australia, vol. 16 (Australian Government Publishing Service: Canberra). 
de Queiroz, K. \& Donoghue, M.J. (1988) Phylogenetic systematics and the species problem. Cladistics 4: 317-338.

de Queiroz, K. \& Donoghue, M.J. (1990a) Phylogenetic systematics and species revisited. Cladistics 6: 83-90.

de Queiroz, K. \& Donoghue, M.J. (1990b) Phylogenetic systematics or Nelson's version of cladistics? Cladistics 6: 61-75.

de Queiroz, K. \& Gauthier, J. (1990) Phylogeny as a central principle in taxonomy: phylogenetic definitions of taxon names. Systematic Zoology 39: 307-322.

de Queiroz, K. \& Gauthier, J. (1992) Phylogenetic taxonomy. Annual Review of Ecology and Systematics 23: $449-480$.

Donoghue, M.J. (1985) A critique of the biological species concept and recommendations for a phylogenetic alternative. Bryologist 88: 172-181.

Donoghue, M.J. \& Cantino, P.D. (1988) Paraphyly, ancestors, and the goals of taxonomy: a botanical defense of cladism. Botanical Review 54: 107-128.

Donoghue, M.J., Doyle, J.A., Gauthier, J., Kluge, A.G. \& Rowe, T. (1989) The importance of fossils in phylogeny reconstruction. Annual Review of Ecology and Systematics 20: 431-460.

Eldredge, N. \& Cracraft, J. (1980) Phylogenetic Patterns and the Evolutionary Process (Columbia University Press: New York).

Endler, J.A. (1989) Conceptual and other problems in speciation. Pp. 625-648 in D. Otte \& J.A. Endler (ed.), Speciation and its Consequences (Sinauer Associates: Sunderland).

Faith, D.P. (1991) Cladistic permutation tests for monophyly and nonmonophyly. Systematic Zoology 40: 366-375.

Faith, D.P. \& Cranston, P.S. (1991) Could a cladogram this short have arisen by chance alone?: on permutation tests for cladistic structure. Cladistics 7: 1-28.

Freudenstein, J.V. \& Doyle, J.J. (1994) Plastid DNA, morphological variation, and the phylogenetic species concept: The Corallorhiza maculata (Orchidaceae) complex. Systematic Botany 19: 273-290.

Frost, D.R. \& Kluge, A.G. (1995) A consideration of epistemology in systematic biology, with special reference to species. Cladistics 10: 259-294.

Funk, V.A. (1985) Phylogenetic patterns and hybridization. Annals of the Missouri Botanical Garden 72: $681-715$.

Gauthier, J. (1986) Saurischian monophyly and the origin of birds. Pp. 1-56 in K. Padian (ed.), The Origin of Birds and the Evolution of Flight, vol. 8 (California Academy of Sciences Memoirs).

Grant, P.R. \& Grant, B.R. (1992) Hybridization of bird species. Science 256; 193-197.

Graybeal, A. (1995) Naming species. Systematic Biology 44: 237-250.

Green, D.M. \& Borkin, L.J. (1993) Evolutionary relationships of Eastern Palearctic brown frogs, genus Rana: paraphyly of the 24-chromosome species group and the significance of chromosome number change. Zoological Journal of the Linnean Society 109: 1-25.

Harrison, R.G. (1991) Molecular changes at speciation. Annual Review of Ecology and Systematics 22: 281-308.

Hennig, W. (1966) Phylogenetic Systematics (University of Illinois Press: Urbana).

Hoelzer, G.A. \& Melnick, D.J. (1994) Patterns of speciation and limits to phylogenetic resolution. Trends in Ecology and Evolution 9: 104-107.

Hopper, S.D. \& Burgman, M.A. (1983) Cladistic and phenetic analyses of phylogenetic relationships among populations of Eucalyptus caesia. Australian Journal of Botany 31: 35-49.

Humphries, C.J. \& Chappill, J.A. (1988) Systematics as science: a response to Cronquist. Botanical Review 54: 129-144.

Humphries, C.J. \& Parenti, L.R. (1986) Cladistic Biogeography (Clarendon Press: Oxford).

Kornet, D.J. (1993a) Permanent splits as speciation events: A formal reconstruction of the internodal species concept. Journal of Theoretical Biology 164: 407-435.

Kornet, D.J. (1993b) Reconstructing Species: Demarcations in Genealogical Networks (Rikjsuniversity of Leiden, Netherlands).

Ladiges, P.Y. \& Humphries, C.J. (1986) Relationships in the stringybarks, Eucalyptus L'Herit. informal subgenus Monocalyptus series Capitellatae and Olsenianae: phylogenetic hypotheses, biogeography and classification. Australian Journal of Botany 34: 603-632.

Ladiges, P.Y. \& Whiffin, T. (1993) Taxonomic revision of Eucalyptus alpina s.l. and recognition of three new species, E. victoriana, E. serraensis and E. verrucosa. Australian Systematic Botany 6: 365-370.

Linder, H.P. (1995) Setting conservation priorities - the importance of endemism and phylogeny in the southern African orchid genus Herschelia. Conservation Biology 9: 585-595. 
Lynch, J.D. (1989) The gauge of speciation: on the frequencies of modes of speciation. Pp. 527-553 in D. Otte \& J.A. Endler (ed.), Speciation and Its Consequences (Sinauer Associates Inc.: Sunderland, Massachusetts).

Marginson, J.C. \& Ladiges, P.Y. (1988) Geographical variation in Eucalyptus baxteri s.l. and the recognition of a new species, E. arenacea. Australian Systematic Botany 1: 151-170.

Mayr, E. (1969) Principles of Systematic Zoology (McGraw-Hill: New York).

Mayr, E. (1982) Speciation and macroevolution. Evolution 35: 1119-1132.

Melnick, D.J. \& Hoelzer, G.A. (1993) What is mtDNA good for in the study of primate evolution? Evolutionary Anthropology 2: 2-10.

Melnick, D.J., Hoelzer, G.A., Absher, R. \& Ashley, M.V. (1993) mtDNA diversity in Rhesus Monkeys reveals overestimates of divergence time and paraphyly with neighboring species. Molecular Biology and Evolution 10: 282-295.

Nelson, G. (1989a) Cladistics and evolutionary models. Cladistics 5: 275-289.

Nelson, G. (1989b) Species and taxa: systematics and evolution. Pp. 60-81 in D. Otte \& J.A. Endler (ed.), Speciation and its Consequences (Sinauer Associates: Sunderland).

Nelson, G. \& Platnick, N. (1981) Systematics and Biogeography: Cladistics and Biogeography (Columbia University Press: New York).

Nelson, G. \& Rosen, D.E. (1981) Vicariance Biogeography: A Critique (Columbia University Press: New York).

Nixon, K.C. \& Wheeler, Q.D. (1990) An amplification of the phylogenetic species concept. Cladistics 6: $211-223$.

Nixon, K.C. \& Wheeler, Q.D. (1992) Extinction and the origin of species. Pp. 119-143 in M.J. Novacek \& Q.D. Wheeler (ed.), Extinction and Phylogeny (Columbia University Press: New York).

O'Hara, R.J. (1993) Systematic generalization, historical fate, and the species problem. Systematic Zoology 42: 231-246.

Page, R.D.M. (1989) Comments on component-compatibility in historical biogeography. Cladistics 5: $167-182$.

Page, R.D.M. (1990) Component analysis: a valiant failure? Cladistics 6: 119-136.

Pate, J.S., Kuo, J., Dixon, K.W. \& Crisp, M.D. (1989) Anomalous secondary thickening in roots of Daziesia (Fabaceae) and its taxonomic significance. Botanical Journal of the Linnean Society 99: 175-193.

Patton, J.L. \& Smith, M.F. (1994) Paraphyly, polyphyly, and the nature of species boundaries in pocket gophers (genus Thomomys). Systematic Biology 43: 11-26.

Rage, J.-C. \& Jaeger, J.-J. (1995) The sinking Indian raft: a response to Thewison and McKenna. Systematic Biology 44: 260-264.

Rieppel, O. (1994) Species and history. Pp. 31-50 in R.W. Scotland, D.J. Siebert \& D.M. Williams (ed.), Models in Phylogeny Reconstruction, vol. 52 (Clarendon Press: Oxford).

Rieseberg, L.H., Beckstrom-Sternberg, S.M., Liston, A. \& Arias, D.M. (1991) Phylogenetic and systematic inferences from chloroplast DNA and isozyme variation in Helianthus (Asteraceae). Systematic Botany 16: 50-76.

Rieseberg, L.H. \& Brouillet, L. (1994) Are many plant species paraphyletic? Taxon 43: 21-32.

Rohwer, J.G. \& Kubitzki, K. (1993) Ecogeographical differentiation in Nectandra (Lauraceae), and its historical implications. Botanica Acta 106: 88-99.

Rosen, D.E. (1979) Fishes from the uplands and intermontane basins of Guatemala: Revisionary studies and comparative biogeography. Bulletin of the American Museum of Natural History 162: 267-376.

Sepkoski, J.J. \& Kendrick, D.C. (1993) Numerical experiments with model monophyletic and paraphyletic taxa. Paleobiology 19: 168-184.

Smith, A.B. (1994a) Rooting molecular trees: problems and strategies. Biological Journal of the Linnean Society 51: 279-292.

Smith, A.B. (1994b) Systematics and the Fossil Record: Documenting Evolutionary Patterns (Blackwell Scientific Publications: Oxford).

Smith, G.R. (1992) Introgression in fishes: significance for paleontology, cladistics and evolutionary rates. Systematic Biology 41: 41-57.

Sneath, P.H.A. \& Sokal, R.R. (1973) Numerical Taxonomy: The Principles and Practice of Numerical Classification (W. H. Freeman and Company: San Francisco).

Sokal, R.R. \& Rohlf, F.J. (1981) Biometry (W. H. Freeman and Company: New York).

Swofford, D.L. (1990) PAUP: Phylogenetic Analysis Using Parsimony (Illinois Natural History Survey: Champaign). 
Taylor, J.M. \& Crisp, M.D. (1992) A revision of Chorizema (Leguminosae: Mirbelieae). Australian Systematic Botany 5: 249-335.

Theriot, E. (1992) Clusters, species concepts, and morphological evolution of diatoms. Systematic Biology 41: 141-157.

Thiele, K. (1993a) The holy grail of the perfect character: the cladistic treatment of morphometric data. Cladistics 9: 275-304.

Thiele, K. \& Ladiges, P.Y. (1994) The Banksia integrifolia L.f. species complex (Proteaceae). Australian Systematic Botany 7: 393-408.

Thiele, K.R. (1993b) A Cladistic Analysis of Banksia L.f. (The University of Melbourne).

Vrana, P. \& Wheeler, W. (1992) Individual organisms as terminal entities: laying the species problem to rest. Cladistics 8: 67-72.

Weston, P.H. \& Crisp, M.D. (1994) Cladistic biogeography of Waratahs (Proteaceae: Embothrieae) and their allies across the Pacific. Australian Systematic Botany 7: 225-249.

Wheeler, Q.D. \& Nixon, K.C. (1990) Another way of looking at the species problem: a reply to de Queiroz and Donoghue. Cladistics 6: 77-81.

Whiffin, T. \& Ladiges, P.Y. (1992) Patterns of variation and relationships in the Eucalyptus alpina E. baxteri complex (Myrtaceae) based on leaf volatile oils. Australian Systematic Botany 5: 695-709. Wiley, E.O. (1981) Phylogenetics (John Wiley \& Sons: New York).

Zandee, M. \& Roos, M.C. (1987) Component-compatibility in historical biogeography. Cladistics 3: 305-322. 
Appendix 1. Postulated autapomorphies in species and subspecies from genera in Proteaceae and Fabaceae for which phylogenetic information is available. The third column lists taxa whose taxonomic segregation might have rendered a taxon without an autapomorphy paraphyletic. (Sources: Pate et al. 1989; Crisp 1990; Crisp 1991; Taylor \& Crisp 1992; Weston \& Crisp 1994; Crisp 1995a; Crisp 1995b, as well as original observations.)

\section{Taxon}

Fabaceae: Mirbelieae

Brachysema

bracteolosum

celsianum

latifolium

melanopetalum

minor

modestum

papilio

praemorsum

sericeum

subcordatum

Chorizema

aciculare

subsp. aciculare

subsp. laxum

carinatum

circinale

cordatum

cytisoides

dicksonii

diversifolium

genistoides

glycinifolium

humile

ilicifolium

nanum

nervosum

obtusifolium

parviflorum

racemosum

reticulatum

retrorsum
Autapomorphies

Segregants

modestum

papilio

melanopetalum

subsp. laxum

spathulatum
None

Leaves circinate

Pod distinctly stipitate

Bracteoles and calyx-lobes longer than calyx-tube

Orange-red petals; stigma with a tuft of hairs

Leaves herbaceous; keel obtuse or rounded

Leaves shed at flowering

Leaves heteromorphic, upper ones longer and narrower

Leaves obovate to obcordate

Leaf triangular with elongate apex

Plant and parts diminutive

Leaf apex deflexed

Blunt keel

Racemes condensed

Leaf margins revolute

Long erect stems; ovate leaves

Leaf prickles retrorse; style straight 


\section{Taxon}

rhombeum

rhynchotropis

spathulatum

trigonum

ulotropis

uncinatum

varium

Daviesia

abnormis

acicularis

alata

alternifolia

anceps

angulata

apiculata

arborea

arenaria

argillacea

arthropoda

articulata

asperula

subsp. asperula

subsp. obliqua

audax

benthamii

subsp. acanthodona

subsp. benthamii

subsp. humilis

brachyphylla

brevifolia

bursarioides

buxifolia

campephylla

cardiophylla

aff. cardiophylla

chapmanii

cordata

corymbosa

\section{Autapomorphies}

Stigma oblique; leaves rhombic

Long beak on keel

Distal leaves enlarged

Stems trigonous

Curly keel

Bracteoles ovate

Leaves bullate; inflorescence condensed

Branchlets white-hirsute; flowers cryptic

Leaf margins toothed, revolute

Bracts and calyx fimbriate

Involucral bracts reddish, undulate, pubescent

Leafless with biconvex cladodes

None

Apiculate leaf apex

Arborescent habit; corky bark

Leaf midrib prominent abaxially

Leaves flat, glaucous, smooth; venation obscure

Standard petal minute

Petals persistent in fruit; pedestal at leaf base

Leaves striate and scabrous

None

Leaves scimitar-shaped

Parts very rigid and erect

None

Leaves reduced in size, branchlet-like

None acanthoclona

None

Leaves very short, apically recurved (or none?)

Leaves semi-articulate

Characteristic branching; small obovate leaves

Leaves crenulate, cordate

Oddly shaped leaves, flowers and fruits

None

Large flowers

Broad, very crowded leaves

Phyllodes sagittate with attenuate apex

Corymbose unit inflorescence polyphylla?

subsp. obliqua

purpurascens

subsp.

?.

Segregants

aff. cardiophylla 
Taxon

costata

crassa

crenulata

croniniana

daphnoides

debilior

subsp. debilior

subsp. sinuans

decipiens

decurrens

dielsii

dilatata

discolor

divaricata

elliptica

elongata

subsp. elongata

subsp. implexa

emarginata

epiphyllum

eremaea

euphorbioides

filipes

flava

flexuosa

genistifolia

glossosema

gracilis

grahamii

grossa

hakeoides

subsp. hakeoides

subsp. subnuda

hamata

horrida

incrassata

subsp. incrassata

subsp. reversifolia

\section{Autapomorphies}

Segregants

Calyx 10-ribbed; standard very broad

Clavate, pith-filled leaves

Involucral bracts semi-pungent

Fascicled leaves

None

None (or clawless bracts?)

None

Leafless, branchlets curly

Winged stems; pod reddish to purplish

Decurrent phyllodes

Curly indumentum

Dilated hooked leaves; cluster-like inflorescence

None

Divaricate branching; paired markings on standard

None

Long narrow involucral bracts

None

Spiral leaves; reduction of bracts

Emarginate leaves

'Stag-horn' phylloclades; large red flowers

Long, slender leaves and pedicels

Bizarre cactus-like growth form

Two distinctive longitudinal secondary veins

Unit inflorescence racemose with apical umbel

Flexuose habit; pod purple-spotted

None

asperula?

Unique floral morphology with linguiform standard

Upper two calyx lobes deeply divided

Stipules developed

All parts large and coarse

None

?

None

subsp. subnuda

Leaves minute, spine-like

Leaves rigid, short, hooked

Dimorphic habit

Leaves continuous with branchlets

None

subspp.

reversifolia, teres arborea

buxifolia

emarginata

pseudaphylla

subsp. sinuans

subsp. elongata

Flexuose habit and reflexed leaves 


\section{Taxon}

subsp. teres

inflata

intricata

subsp. intricata

subsp. xiphophylla

laevis

lancifolia

latifolia

laxiflora

leptophylla

lineata

longifolia

major

megacalyx

mesophylla

microcarpa

microphylla

mimosoides

subsp. acris

subsp. mimosoides

mollis

nematophylla

newbeyi

nova-anglica

nudiflora

subsp. amplectens

subsp. drummondii

subsp. hirtella

subsp. nudiflora

obovata

oppositifolia

ovata

oxyclada

oxylobium

pachyloma

pachyphylla

pauciflora

\section{Autapomorphies}

All leaves terete

Inflated pod; pale calyx lobes

Intricate habit; leaves widely spreading

None

Crowded dagger-like leaves

Reticulate venation obscure; rachis short

Resinous with characteristic odour

Crenulate leaves

None

None

Leaves $<1 \mathrm{~mm}$ diam., finely striate; flowers $1-2$

Upper calyx-lobes outcurved

Pod viscid

Leaves narrow-obovate, bright green; flower 1

Habit procumbent; summer-flowering; long pedicel

Leaves angular-terete; unbranched

Branchlets short, spinescent, divaricate

None

Leaves obovate or elliptic

None

Softly hirsute

Leaves terete and sinuous

Pedicel bent; bracts canaliculate

Slightly enlarged bracts

None

Amplexicaul leaves

None

None?

None?

Leaves spathulate, glaucous, wrinkled

Coriaceous, cucullate involucral bracts

Leaves ovate or elliptic

Rigid spinescent branchlets

Leaf shape, especially striations

Conspicuous stipules; thickened leaf margins

Bizarre pith-filled leaves; waxy bloom

Wings centrally constricted; flowers $1-3$
Segregants

subsp. xiphophylla

D. Iatifolia clade grahamii and newbeyi

buxifolia and elliptica

subsp. acris

uniflora

$?$

subsp. nudiflora?

subsp. hirtella? 
Taxon

pectinata

pedunculata

physodes

pleurophylla

podophylla

polyphylla

preissii

pseudaphylla

pteroclada

pubigera

purpurascens

quadrilatera

quoquoversus

ramosissima

reclinata

retrorsa

rhizomata

rhombifolia

rubiginosa

sarissa

subsp. redacta

subsp. sarissa

scoparia

smithiorum

speciosa

spinosissima

spiralis

squarrosa

striata

stricta

suaveolens

teretifolia

tortuosa

triflora

trigonophylla

ulicifolia

umbellulata

uncinata

\section{Autapomorphies}

Prominent vein near adaxial margin; long rachis

Branchlets pruinose; long peduncles; viscid pedicels

None

oxyclada

Straw-coloured nodes and ribs

Pseudopetiole

Reduced inflorescences

Leaves falcate, narrowed towards base

Standard abaxially dark purple with yellow streak

Leafless winged cladodes

Leaves very convex; distinctive rachis

Plant purplish; pods semiglobose

Branchlets angular; inflorescence umbelliform

Irregular hairs

Intricate, arching branchlets; large flowers

Robust rachis; accrescent papery calyx

Retrorse leaves; small pod

Clonal, rhizomatous habit

Rhombic leaves; fascicled inflorescence

Plastic leaves; caducous bracts

Thick smooth rigid leaves; bract striations

None

subsp. sarissa

Bracts concealing inflorescence

Broombush habit

Pruinose stems; hooked leaves

Bizarre growth habit; big red flowers

Leaves very crowded with thickened bases

Spiral phyllodes

Upper calyx-lobes falcate

Pruinose; leaves to $6 \mathrm{~mm}$ broad

Calyx accrescent, viscid, lobes recurved

Reduced inflorescence; long calyx-lobes

None

grossa

Zigzag growth habit; wrinkled inverted leaves

Inflorescence 3-flowered

Triquetrous leaves

None

See text

None

Hooked leaves; acicular-beaked keel 
Taxon

unifiora

villifera

wyattiana

Proteaceae: Embothrieae

Alloxylon

brachycarpum

flammeum

pinnatum

wickhamii

Embothrium

coccineum

Lomatia

arborescens

dentata

ferruginea

fraseri

fraxinifolia

hirsuta

ilicifolia

myricoides

polymorpha

silaifolia

tasmanica

tinctoria

Oreocallis

grandiffora

mucronata

Telopea

aspera

mongaensis

oreades

speciosissima

truncata

\section{Autapomorphies}

Leaves appressed with recurved tips; peaked standard

None

Linear leaves; long pedicels and peduncles

\section{Segregants}

quoquoversus

flammeum

First seedling leaves trifid

Adult leaves pinnate to pinnatisect; venation eucamptodromous; leaves concolorous

Perianth dilated

Pollen biporate, with looped elements

None

myricoides, fraseri

Gynoecium densely hairy; conflorescence reduced; stomata in crypts

Conflorescence basipetal; phyllotaxis decussate; flowering SGUs all axillary; leaf abaxially rough; perianth maroon \& yellow

Auxilliary conflorescences present;

leaf hairy abaxially

None

$?$

Cataphylls clustered and broad;

phyllotaxis distichous

Prominent leaf venation

Long narrow leaves

Leaf hairy abaxially

None

ilicifolia

Perianth maroon

None

$?$

mucronata

Axes glaucous; flower buds erect; flowers pale

Leaves harsh, rusty hairy

Sclereids absent

None

mongaensis

None

aspera

Bent styles; bracts rusty hairy 